\title{
Reprogramming Modernist Heritage: Enhancing Social Wellbeing by Value-Based Programming Approach in Architectural Design
}

\author{
Jelena Ristić Trajković $\mathbb{B}$, Aleksandra Milovanović * ${ }^{\mathbb{D}}$ and Ana Nikezić \\ Faculty of Architecture, University of Belgrade, 11000 Belgrade, Serbia; jelena.ristic@arh.bg.ac.rs (J.R.T.); \\ ana.nikezic@arh.bg.ac.rs (A.N.) \\ * Correspondence: alekmil@arh.bg.ac.rs
}

\section{check for}

updates

Citation: Ristić Trajković, J.; Milovanović, A.; Nikezić, A. Reprogramming Modernist Heritage: Enhancing Social Wellbeing by Value-Based Programming Approach in Architectural Design. Sustainability 2021, 13, 11111. https://doi.org/ $10.3390 /$ su131911111

Academic Editors: Ana Pastor Pérez, David Barreiro Martínez and Eva Parga Dans

Received: 22 August 2021

Accepted: 4 October 2021

Published: 8 October 2021

Publisher's Note: MDPI stays neutral with regard to jurisdictional claims in published maps and institutional affiliations.

Copyright: (c) 2021 by the authors. Licensee MDPI, Basel, Switzerland. This article is an open access article distributed under the terms and conditions of the Creative Commons Attribution (CC BY) license (https:// creativecommons.org/licenses/by/ $4.0 /)$.
Abstract: This paper is built on the assumption that architecture is the establishment of the relationship between past and future, built and unbuilt, within the inherited and natural context and in direct connection with the overall culture. Unlike a traditional approach to heritage generally limited to considering only the visible values of the place, this research stands on the belief that, in the context of heritage, the implementation and application of behavioral knowledge in architectural discourse contributes to the intensification and enhancement of these relations. In accordance with the need to re-examine existing and explore new forms of the relationship between future life of heritage and social wellbeing, the main goal of the research is to examine the possibility of improving this relationship through a value-based architectural programming methodological framework. This paper was conducted through: (1) theoretical framework that intertwines environment-behavior theories and architectural programming as the value-matrix methodology for the reuse of heritage; (2) exploring the established framework through design results gathered within the design-based studio on "heritage reprogramming" at the University of Belgrade-Faculty of Architecture with a particular focus on the modernist architectural heritage; and (3) discussing the overall principles through the multiscale and value-based approach. The evaluation of the results indicates the possibility of improving the social dimension of heritage protection and reuse, as well as the need to shift the focus from exclusively material and formal values of heritage to social and cultural aspects in accordance with the needs of contemporary society and culture. Results indicate that the multidimensional nature of architectural programming methodological approach in the context of modern heritage and, accordingly, the synergy of different programming values (environmental, human, social, systemic, temporal, economic, aesthetic) provides sustainable access to heritage and has the capacity to improve the social wellbeing of individual users but also of the wider community.

Keywords: architectural programming; heritage; modernist architecture; value-based matrix; architectural design studio; environment-behavior relations; Genex tower; New Belgrade

\section{Introduction}

The current city transformation development trends indicate that, in addition to the unprecedented growth in the global building sector, nearly two-thirds of the building area that exists today will still exist in 2050 [1]. That is why the continuous re-examination of current research approaches concerning evaluation, (re)planning and (re)designing of the inherited space represents a necessary and challenging task for researchers, educators, policymakers and practitioners in the field of architecture and urbanism. This is confirmed by a series of affirmative and research-stimulating declarations, policy positions and strategies aimed at the practical arena of architecture. The EU Council Work Plan for Culture 2019-2022 [2] denotes architecture as a cross-cutting field and "as a discipline that encompasses the right balance between cultural, social, economic, environmental and technical aspects for the common good". Additionally, according to the First EU 
Policy outline on Architecture, this disciplinary framework is flagged as "the heritage of tomorrow" [3]. In line with this notion, the identification of urban patterns whose values have not yet been recognized and which have a capacity to become heritage of the future requires innovation in approaches and methodologies for their decoding. In this regard, research challenges are becoming two-fold: on one side towards architectural strategies for reusing or reviving architectural heritage and on the other towards critical strategies for identifying the hidden values of spatial patterns that will constitute the future heritage. In such a contextual framework, the development of new and the review of existing value-based design strategies is a leading research issue that will be opened in this paper.

This research starts from the premise that substantial aspects of design are closely focused on physical determinants of space and physiological issues of comfort (acoustics, heat and sound), neglecting the closest link between the user and the environment in which the intellectual and emotional comfort of the user is concentrated [4]. This also implies the neutralization of the social components of space at different spatial levels-from the setting of user activity to the cultural landscape. The direction for bridging this gap is highlighted in the Policy Position by the Architects' Council of Europe (ACE) on comprehensive urban regeneration, which stresses that architectural action requires taking into consideration holistic approach and all scales, as well as the economic, social, environmental and cultural aspects affecting the built environment [5]. The multiscale approach is recognized as a leading perspective for achieving a reflexive dialogue between heritage and contemporary architecture within the Leeuwarden Declaration (Adaptive Re-use of the Built Heritage: Preserving and Enhancing the Values of our Built Heritage for Future Generations), pointing out that heritage entities should be understood in their broader context in order to argumentatively establish value framework in line with the critical urban environment [6]. In that direction, a focus on a multifaceted design action offers a powerful mechanism for achieving sustainable space configurations between people, activities and relationships. Similarly, the "sustainable by design" strategy recognizes that architecture is part of a complex interactive system, linked to the broader contextual framework and reflected towards the heritage, culture and social values of the community's daily life [7].

In order to critically review all of the above research challenges, this paper is built on the starting points that (1) architecture is not just the design of space but the establishment of relations within that space (specifically the relationship between heritage, built and natural context and overall culture) and that (2) the implementation and application of behavioral knowledge in architectural discourse in the context of heritage contributes to the intensification and improvement of these relations. In accordance with the need to re-examine existing and explore new forms of the relationship between heritage and social wellbeing, the operational goal of the research is to examine the possibility of improving this relationship through the value-based methodological framework of architectural programming. The assumption is that the responses of architectural practice to the needs of contemporary society and culture regarding heritage, especially from the aspect of enhancing social wellbeing, can be continuously improved.

Studies on programming in architecture have emerged as the embodiment of a systematic framework of "analysis-synthesis" [8] by bringing it into close connection with the general framework of research by design [9]. Architectural programming is an analytical and problem-based method in the design process, oriented towards decoding contextual values and establishing design goals. Although it originates from the domain of computer programming and system analysis [10], within architecture, programming implies the procedural aspect of data collection, analysis, problem and values identification. Accordingly, architectural programming has a role in generating operational knowledge for the design process. This paper highlights a value-based approach in architectural programming and demonstrates its application in reprogramming modernist heritage in order to enhance social well-being. 
The contribution of this paper to architectural and urban design, as well as the linkage in-between architectural and behavioral studies, can be described on three levels. The first level establishes the framework by intertwining two diverse theoretical grounds: (1) environment-behavior theories for the architectural practice and (2) architectural programming as the value-matrix methodology for the reuse of heritage. On the second level, the described theoretical framework was employed within the design-based Master level studio on "heritage reprogramming" at the University of Belgrade-Faculty of Architecture, focusing on the modernist architectural heritage (case study of Genex Tower in New Belgrade, Serbia). On the third level, a qualitative analysis of heritage reprogramming conceptual models was performed through a multiscale and value-based approach and in line with targeted social dimensions of wellbeing.

Hence, the paper evolves through four sections:

- Theoretical background: explanation of the synergetic relationship of environmentbehavior theories and methodology of architectural programming with particular focus on value-based approach;

- Materials and methods: explanation of the research design and case study;

- Findings and discussion: recognition of key reprogramming perspectives (conceptual models) in line with relevant spatial levels;

- Concluding remarks.

The fact that Genex Tower is one of the most important and authentic modernist heritage realizations in Serbia and ex-Yugoslavia (recognized by Docomomo SerbiaInternational Committee for Documentation and Conservation of Buildings, Sites and Neighbourhoods of the Modern Movement) gives particular relevance to the research. In 2019, Genex Tower was presented at the MOMA exhibition "Toward a Concrete UtopiaArchitecture in Yugoslavia, 1948-1980" as one of the "exceptional works of socialist Yugoslavia's leading architects to the international audience for the first time, highlighting a significant yet thus-far understudied body of modernist architecture, whose forwardthinking contributions still resonate today" [11].

\section{Theoretical Background}

\subsection{Environment-Behavior Relations and Architectural Design-Significance, Concepts and Directions}

The role of the environment in understanding social processes has pointed out the necessity of implementing environment-behavior knowledge in architectural practice. The recognition that architecture and urbanism usually do not take into account and consider people's behavior and individual perception, as well as desires, social norms and dynamics, cultural values and expectations in their planning perspectives, initiated the methodological framework that enables the implementation of this knowledge in architectural design. In that context, architectural programming was introduced as the methodological framework for (1) searching for an answer to systematic and operational assessment in planning and design, (2) the systematization and selection of relevant information in this complex process and (3) the identification of problem which becomes the object of solving through the design process.

Environment-behavior sciences arose to develop an empirically based understanding of the reciprocal interactions between individuals, social groups, culture and the environment in which they live, aiming to apply this knowledge in planning and designing the built environment. Thus, environment-behavior studies include the research of mutual and reciprocal interactions of people and the environment on all scales (spatial levels) and application of this knowledge to improve the quality of life and the identity of space through design, planning and environmental policy. Accordingly, these studies focus on the dependence of the environmental and sociocultural systems, including, before all else, environmental and human factors. They operate on the individual, group, society and culture levels and include environmental changes that people carry out through their 
activities at different spatial levels. This area also includes research into the political, social and economic context of environment-behavior relations [12].

\subsubsection{The Paradigm Shift: From Modernist Determinism to Contemporary Transactionalism}

Since the middle of the last century, understanding the relations between people and the environment has changed significantly [13-16].

The modernist doctrine in architecture relied on a deterministic paradigm. It was based on the view that the environment determines human behavior. As stated above, environment, and thus architecture, was considered the "main" determining factor, and people were subjects who are dependent on the conditions imposed by the environment. According to Broady, this view implies a one-way process in which a good physical environment thus produces good social effects [17]. This approach fully corresponded to the political goals of socialist ideology, which indicates that architectural paradigms have been shaped concerning the ideological implications of society [12]. In this sense, modernist architecture symbolized progress and a new vision of a new social order. Designing a complicated scheme of the organization of a new society and human life itself was at the top of the list of socialist architecture's priorities [12]. The new modernist urban ambiences are shaped following the ideological principles of socialism. This approach has had a significant impact on design practice and the development of architectural programming with a focus on "user requirements" [12].

However, there has been growing criticisms since the 1970s against most modernist built environments, especially regarding their standardization and prefabrication of building elements, that led to devastating uniformity, monotony, boredom and superconcentration in collective "housing machines" of international style [18]. Dayaratne states that understanding that the relations between people and physical settings are not as direct and causal as the deterministic paradigm suggested has led to changes of this model, adding meaning and other attributes as intermediary factors interacting between people and their environments. Those who focused on the idea of meaning proposed that the meaning people assign to the environment mediates the effects the environment has for people and that such meanings are both given and modified by people themselves [13].

Observing the contemporary context of research and practice of architecture, it is clear that the relations between people and the environment are causal. Canter points out that the influence of people on their environments may be much more than mere modifications of the impact of those surroundings. People may completely change the nature of their surroundings and the meanings they have. If not by physical interventions in space, then by what they do there or the way they think of the physical setting [19]. This starting point corresponds to the model of the transactional paradigm.

In the transactional model, people and environments are not considered separate, static entities but continuously evolving organisms with mutual impact and interactions. In the context of heritage, it is important to highlight Canter's standpoint that "to distinguish between action and context and to assume that past relationships between them have the same function in the present is illogical because both the organism and the environments are evolving together" [20].

\subsubsection{Investigation of the Reciprocal Interactions among Places, People, Culture and Time}

Within different environment-behavior paradigms, a large number of theoretical concepts and research methodologies have emerged. The most prominent among them observes the environment as a system of settings in which the system of activities can be observed [21].

The model for reviewing the scope of available environment-behavior information was initially proposed by psychologist Irwin Altman and involves three main components: behavioral phenomena/concepts, user groups and places/settings [22]. Socio-behavioralcultural phenomena imply different aspects of human behavior concerning everyday physical environments: cultural values, social interaction, experience, perception, etc. 
Different user groups have different needs, characteristics (culture, lifecycles, lifestyles), use patterns and, accordingly, differently influence the quality of the environment. Places include all scales of settings, from room scale to region [23]. Socio-political-economiccontextual issues are to be read concerning these three components only through a temporal perspective. This model has a central position in creating conceptual models of heritage reprogramming in the context of the subject research.

\subsubsection{Current Perspectives on Pro-Environmental Behavior and the Value-Belief-Norm Theory}

In the context of current urgent issues considering sustainability and social wellbeing, contemporary perspectives in environment-behavior sciences are dominantly focused on pro-environmental behavior/citizenship. Most of the current environmental problems are dominantly the outcomes of individual actions and the activities driven by economic interests. At the same time, the healthiness of the global economy and people are inextricably interdependent on the wellbeing of the environment. Pro-environmental behavior is defined as actions directed to protect the environment as a whole and/or a specific ecosystem from the destructive effects of human activities [24,25]. This interdependence implies an urgent need to profoundly understand the patterns, systems, relations and causes of environmental degradation. Different theories and models are developed to explain and predict human behavior on one side and enhance the understanding and solving of contemporary environmental problems on the other side (primitive models [26,27], environmental citizenship model [26], planned behavior model [28,29], the value-belief-norm theory of environmentalism [25,30], model of human interaction with the environment [31], health belief model [32], etc.). It is essential to develop and incorporate these aspects into environmental education in the context of all disciplines that have a role in shaping and transforming our built and natural environment.

The value-belief-norm theory has a special significance in the context of the valuebased architectural programming approach. It was proposed by Stern $[25,33]$ to explicate the influence of human values on behavior in specific environments. The topology of human values relies on Schwartz classification, which maps all human values into 10 value types and 4 broader value clusters or orientations arrayed in particular relationships to each other: openness to change (including hedonism, self-direction and stimulation) vs. conservation (tradition, conformity, security) and self-enhancement (power, achievement) vs. self-transcendence (universalism, benevolence) [34,35]. This theory establishes relationships between values, beliefs, norms and behaviors within the cause-and-effect chain [25,33]. Relevant research [30] has shown that the value-belief-norm cluster of variables was far stronger in predicting each behavioral indicator than the other theories, even when other theories were taken in combination. Considering the abovementioned theories and models, the value-belief-norm theory provides a more elucidative explanation of human-environment interactions and how these interactions can affect each other, having in mind a relatively ample number of variables responsible for cause and action [16]. A value-belief-norm model is a promising tool for explaining and promoting pro-environmental actions such as active participation and attachment to the heritage environment. It seeks to answer the question of what influences individuals' interest and participation in the immediate environment, or, more precisely, pro-movement action that creates a predisposition to provide support for social movements (citizenship actions, policy support and acceptance and personal-sphere behaviors that help restore recognized values experience) [32]. The value-belief-norm theory states that relatively stable and general factors, that is, values and environmental concern, affect behavior-specific variables (i.e., problem awareness, outcome efficacy and personal norm), which in turn influence behavior. The higher the problem awareness is, the higher is one's environmental concern. At the same time, environmental concern is influenced by people's values [36]. Abovementioned categories of human values affect behavior specific variables (problem awareness, personal norms, etc.), which in return influence behavior [36]. For example, traditional values reflecting the extent to which people care about the preservation of inherited identity values. 
Many researchers recognized social norms as an important antecedent to behavior [37]. Attachment to place can have an essential role in mediating between environmental beliefs and intentions to engage in pro-environmental behavior. Accordingly, environment/place identity, namely, heritage identity as a whole, has a vital role in mediating effect in influencing citizens' environmental behavior. This theory helps to enhance our understanding and recognition of values, beliefs and norms that influence citizens behavior. It also has implications for design in terms of significant inputs on human needs and norms that are key to design decisions. Through more effective information transmission and user needs evaluation, this theory enables the implementation of behavioral knowledge into architectural design's methodological framework in order to achieve environmental and cultural sustainability of architectural heritage.

\subsubsection{Environment-Behavior Relations and Social Wellbeing}

The preliminary footstep towards understanding the relationship between social wellbeing and environmental issues (both ecological, economic and social) is to examine environment-behavior relations as a starting point for their understanding. Implementing environment-behavior knowledge enables us to understand and change the target behavior that stands detrimental to the living environment.

This paper starts from the premise that implementation of environment-behavior knowledge regarding the specific cultural context in architectural design results in enhancing social aspects of wellbeing. In line with that, wellbeing is observed as a social concept beyond the psychological aspects of an individual or a group [38]. Although wellbeing is, in essence, a subjective term, it refers to a state of being for individuals or groups that is often evaluated against a set of social ideals, which in itself indicates that wellbeing is a social construct [39]. In line with that, it is important to point out that wellbeing is a multidimensional concept that changes in the spatial and temporal dimensions. It changes in time, place and culture [40]. In addition to the physical health dimension that is undoubtedly most often associated with wellbeing, social dimensions represent an inseparable and essential part of wellbeing from the aspect of enhancing the sustainability, environmental sensitivity, and resilience of urban areas. The Rio +20 Conference points out the importance of physical, mental and social wellbeing for sustainable development. This document indicates the importance of a new paradigm beyond environmental improvement, focusing on social and economic dimensions of wellbeing [41]. As Nocca states, when considering cultural heritage as a common good, any activity aiming at preserving or valorizing is able to produce benefits for the community in which it is placed [40]. Namely, cultural heritage can play a critical role in achieving the new humanistic and ecological paradigm of sustainable cities. [42]. Nocca develops a set of multidimensional indicator matrix as a first step towards a new effective approach able to support the recognition of the key role of cultural heritage in sustainable development and effective tool to produce empirical evidence about the impacts of cultural urban landscape conservation/regeneration on overall wellbeing [42]. It is essential to understand the heritage context in which we live, i.e., our living standards and needs (access to education, participation in political life, living standards, spiritual fulfilment, state of health, economic security, attachment to place, access to community resources, level of stressors, pleasantness and safety, cultural diversity and social acceptance, community connections, etc.).

Recent research on the multidimensional impacts of cultural landscape conservation/regeneration has shown that a set of indicators to assess the role of cultural heritage in sustainable development (and thus the multidimensional benefits produced by cultural heritage conservation/valorization) is urgently required [40].

\subsection{Methodology of Architectural Programming}

Architectural programming is recognized as an analytical and problem-based approach in the design process raised in specific contextual circumstances of exponential urban development and urbanity growth, including changing patterns of everyday life, 
industrialization, mass construction, and standardization [10]. In its contextual framework, the architectural programming methodology was created with the aspiration to (a) develop new spatial patterns and typologies in an effective, critical and argumentatively based way and to (b) provide the high performance and functionality of the space. In rendering the programming methodology from its origin (problem-based approach) [43] towards the rehabilitation from the modernist doctrine (hybrid-oriented approach) [44], today, when cities experience a limited capacity state, one of the central design issues is focused on reprogramming existing typologies of inherited spaces. Some studies have already shown the potential of applying architectural programming in the context of architectural heritage, revealing a new "RE" nature of programming directed towards providing a sustainable configuration of activities, spaces and relationships [45].

The origins of the methodological framework of programming in architectural design discourse were established by Pena and Caudill, who in 1959 published a study entitled "Architectural Analysis-Prelude for Good Design" [46], guided by the belief that the design can be significantly improved by "asking the right questions at the right time" [46]. Building the argument on their own design practice, the authors open a critical discussion on the status of the architectural program emphasizing the need to affirm the process nature of the program and establish its methodological orientation-programming as "architectural diagnostics" [46] - the process of establishing specific a set of design criteria through a participatory process that necessarily precedes the beginning of design.

The transposition of aspects from social and behavioral sciences into architectural design contributes to developing specific methodological approaches in programming and design. More specifically, behavioral theories have had a significant impact on the domain of architectural programming in the 1970s, primarily by strengthening designers' argumentative frameworks to describe architectural solutions, understand different phenomena in controlled environments and develop appropriate solutions for specific programming requirements according to identified design problems. The growing interest in the social sciences [47-49] and domains such as environmental psychology, environmental sociology and social ecology has also influenced the growing concern of the academic and professional community that architectural structures and the built environment may have a detrimental impact on people and the environment. In such a context, the user's position in the design process becomes significantly more autonomous and focused on the interdisciplinary study of human needs and behaviors, an input parameter for the programming.

The original position of this view was established by Horowitz [50], pointing out the need to improve the methodological nature of programming through its empowerment with methods, techniques and tools developed by social scientists (such as systematic observation, controlled interviews, questionnaires and surveys and statistical analysis) and, for the purpose of extensive research, focused on gaining knowledge on the needs of different user groups. At the same time, environmental scientists recognized the potential of architectural programming for reformulating goals of functionality [51]. That would provide a critical context for exploring a possible solution to the then-growing controversy of sustainable environmental design. Studer and Stea [51] thus indicate that the functional origin of environmental problems is not in the domain of physical entities but in the "behavioral topographies" of human participants. Although, since the early establishment of the conceptual nature of the architectural program, there has been a focus on strengthening the social component and environmental sensitivity of the built environment and architecture through understanding the architectural program as a "fragment of social pattern" [52] or "lifestyle description" [53]. This component's practical application and articulation did not revive that social essence but rather had a strictly functionalist foundation closely linked to modernist architecture's precedents.

With the development of a methodological framework concerning design methods' paradigm shifts, specific programming approaches have also evolved. These approaches range from a participatory framework that engages future users' proactive involvement to carefully articulated research studies covering complementary typologies and users. In this 
range, there are three groups of approaches: (1) design-based, which is characterized by parallel implementation with the design process in which programming acts as an interface for translating an idea into a design solution; (2) knowledge-based, which has its original position in programming complex and organizationally specific typologies intended for specific user groups; (3) agreement-based [43,54], which is built on the organizational aspect of the design process, while value-based [55] is recognized as the most referenced approach in line with heritage construct.

The value-based architectural programming approach starts from the belief that in the design process, the primary responsibility in the process of architectural programming is the articulation of values that the architect should respond to. Values in this context mean those beliefs, philosophies, ideologies, understandings, purposes or other deeply rooted ideas, which are the reason for creating a design solution and which influence the designed architectural framework [55]. According to Avrami and Mason, values have long underpinned concepts of heritage and its conservation within the built environment [56]. The same authors pointed out that the last half-century bore witness to a critical period of political and social influence that shaped the field's institutional and professional development and has broadened the understanding of how multiple publics may ascribe different values to heritage [56]. In light of a review of published literature on heritage values, Fredheim states that value typologies for heritage conservation and management are often designed and implemented without understanding the implicit consequences of the inclusion and omission of 'values' [57]. He also suggests that these typologies often fail to prompt the necessary questions to develop satisfactorily detailed understandings of heritage significance, resulting in decisions based on implicit, rather than explicit, value assessments in practice. Thus, values in the context of heritage have numerous classifications, meanings and interpretations depending on user groups, context, purpose, etc. According to Hershberger [55], there is no finite set of values applicable to all architectural problems, but there may be sets of values that apply to certain types of architectural problems (see Table 1). In this sense, only specifically and contextually based values can serve as a valuable framework for generating an architectural program. Although many authors have tried to offer a conceptual framework of information matrix with values, in most cases, it did not prove to be a relative framework precisely because of the mentioned variability of values concerning the context and type of architectural problem solved through the design process.

Table 1. Programming value matrix according to Hershberger $[55,58]$.

\begin{tabular}{|c|c|c|c|c|c|c|c|}
\hline Values & Environmental & Human & Social & Systemic & Temporal & Economic & Aesthetic \\
\hline Indicators & $\begin{array}{l}\text { location } \\
\text { climate } \\
\text { urban context } \\
\text { regional } \\
\text { context }\end{array}$ & $\begin{array}{c}\text { physical } \\
\text { physiological } \\
\text { psychological } \\
\text { functional }\end{array}$ & $\begin{array}{l}\text { cultural } \\
\text { legal } \\
\text { common }\end{array}$ & $\begin{array}{l}\text { materials } \\
\text { technologies } \\
\text { processes }\end{array}$ & $\begin{array}{l}\text { growth } \\
\text { change } \\
\text { constancy }\end{array}$ & $\begin{array}{l}\text { building costs } \\
\text { operationalization } \\
\text { maintenance }\end{array}$ & $\begin{array}{l}\text { form } \\
\text { space } \\
\text { style } \\
\text { tradition }\end{array}$ \\
\hline
\end{tabular}

Based on the synergetic relationship of environment-behavior studies and architectural programming, the research thus starts from the belief that this methodological framework can provide a lens for the development of an information background oriented towards the closer connection of people and the environment. In this sense, programming will be activated as an analytical method for observing the social dimension of heritage in accordance with the capacity to perceive and dissect all layers of inherited space-through different spatial and social levels-but so that the environment-user-behavior relationship is established as transactional.

\section{Contemporary Nature of the Architectural Program}

The contemporary theoretical framework of studying the nature and state of the architectural program in design practice is considered on three relationships: (1) hybrid re- 
lations of program elements, (2) relation of program and form and (3) relations of functions (functional performance of space). Dynamic relationships are defined by combining activities and changing conditions-creating scenarios and modes of space use in accordance with the season, environmental conditions or climatic characteristics. Such a framework of architectural program consideration conditioned the research of complex spatial-program configurations that arise concerning users' specificity, relationships, behaviors and tendencies.

A significant step forward in establishing a new nature of the architectural program was made by Fenton [59] by considering the broader scope of hybrid construct in architecture and particularly hybrid relations in-between programs and forms. Based on the configuration and interaction of program elements, two types of hybrid programs have been identified: (1) thematic program - characterized by a dependence between parts and encouraging their interaction, emphasizing the fragmentation of a form and singleness of function between the various assembled elements; and (2) disparate programcharacterized by the pursuit of economic benefits through often adding non-complementary functions to the existing architectural framework, which usually results in unexpected functional configurations.

Guided by the belief that the architectural program relies on repetition and habit and illuminating its prescriptive nature, Tschumi [60] identified that the program is never neutral and that the relationship between program and form can be one of reciprocity, indifference or conflict: (1) reciprocity means shaping the program so that it coincides with the form or shapes the form so that it reciprocates the configuration assigned to the program, (2) indifference implies that the form can accommodate any program, often resulting in a deterministic form and an indeterminate program, while (3) conflict implies that programs and forms intentionally collide to generate unexpected events in space.

To indicate the dynamic nature of the program, James and Yoos [61] single out two types of programs according to functional performance: (1) prescriptive (hard) - described as fixed spaces necessary for basic operation and services; and (2) spontaneous (soft) described as physically porous spaces involving variable activities. In such a research framework, programming is established as an analytical process, and the program is defined as an instrument that contributes to spatial-program configurations that become the primary criterion for typological classification in response to environmental conditions and behavioral possibilities.

Previously singled out perspectives of the architectural program indicate this construct's strong capacity to improve the performance of space and create new configurations, which is especially important in the context of heritage reprogramming where the new order is most often sought. Table 2 provides a recapitulation of the types of architectural programs, and this framework will be particularly important in the context of the design-based research methodology discussion.

Table 2. Types of Architectural program according to [59-61].

\begin{tabular}{ccccccc}
\multicolumn{2}{c}{ Hybrid Relations of Program Elements } & \multicolumn{2}{c}{ Relations of Program and Form } & \multicolumn{2}{c}{ Functional Performance Relations } \\
\hline thematic & disparate & reciprocity & indifference & conflict & prescriptive & spontaneous \\
\hline
\end{tabular}

\section{Materials and Methods}

\subsection{Research Design}

Since the discipline of architecture and, in particular, the field of architectural design are platforms through which the present research operates, the suggested methodology engages research by design and architectural programming in the first phase and qualitative data analysis as an argumentative systematization in the second phase. In line with this, the first phase is focused on exploring heritage reprogramming perspectives towards the establishment of particular conceptual models, while the second is focused on explaining identified perspectives in line with the programming value matrix and multiscale approach. 
While the first is speculative and subjective embedded in the local context, the second is obtained on the general level and is mainly universal in defining conceptual principles for modernist heritage reprogramming.

\subsubsection{First Phase—-Heritage Reprogramming Perspectives: Development of Conceptual Models}

This part of the research was conducted in a studio-based environment, and different concepts were explored within a given spatial framework, further explained within the Case Study section. The research was challenged (1) within the Study module-Design studio on "heritage reprogramming" at the University of Belgrade-Faculty of Architecture, which involved 12 students (1st year of Master Academic Studies in Architecture-Module Architecture) from February to May 2021, and (2) within the context of Erasmus + Strategic Partnerships for Higher Education entitled Enhancing of Heritage Awareness and Sustainability of Built Environment in Architectural and Urban Design Higher Education (HERSUS).

The study module-Design studio consists of a Design project followed by a Seminar and a Workshop. Seminar and Workshop have the intention to methodologically, thematically and theoretically following the design project. In this case, the Seminar was twofold. On one side, students investigated the particular XX century heritage through its tangible and intangible characteristics: architectonics, ideology, meaning, memory and context. On the other side, they were introduced with programming values and indicators for identifying and establishing those values to test their potential as a methodological medium in the design process. The workshop had a role in the effective development of the architectural program through a diagram. The Design studio was carried on in two steps: (a) the analytical step resulting in recognized programming values followed by a set of diagrams explaining the reprogramming process, and (b) the evolving step resulting in conceptual models followed by architectural design solutions. Both steps were developed and tested through a multiscale approach and territorial frames, scaling up and down from the level of landscape to the level of detail (from scale 1:5000 to scale 1:25).

The establishment of heritage reprogramming perspectives was guided by exploring different design solutions on the basis of individual and creative interpretation of the context, individual beliefs, values and aspirations [62] and through inquiry-based and process-centered design pedagogy [63]. It was resolved in harmony with the theoretical background focusing on environment-behavior phenomena/concepts, which stimulate user-centered and social-oriented approaches to heritage.

The exploratory phase was tested through three different steps:

- Historical-interpretative and Typo-morphological exploration of modernist architecture heritage that studies the relationship between (re)programming and heritage values;

- Setting up design perspectives that sift and verify the relationship between everyday life and architecture;

- Conceptual modelling that tests various spatial articulations and interventions.

\subsubsection{Second Phase-Multiscale and Value-Based Heritage Reprogramming Perspectives}

This research phase was conducted as a qualitative data analysis based on 12 design proposals resolved and carried out in the first phase. It is a multi-comparative analysis by nature as it recognizes, combines, systematizes and synthesizes individual proposals creating a unique and universal agenda for modernist heritage reprogramming.

The explanatory phase was performed through three steps:

- Recognition of key programming values for reprogramming modernist heritage embedded in the proposed conceptual models;

- $\quad$ Pointing out relevant spatial levels for reprogramming modernist heritage embedded in the proposed conceptual models;

- Identification of targeted social dimensions of wellbeing in proposed conceptual models. 


\subsection{Qualitative Data Analysis}

This research starts from an interpretative approach to qualitative data analysis [64] based on the recognition that in architectural design research, artefacts, buildings and settings are often seen as the "text" that is the subject of interpretation and reinterpretation [65]. In that respect, design proposals datasets that illustrate conceptual models for heritage reprogramming represent a central framework for qualitative assessment. In order to establish a comprehensive analysis of the proposed conceptual models, it was conducted in two main cross-cutting tracks: (1) analysis in line with programming values (value track) and (2) analysis in line with spatial levels (multiscale track).

The Value Analysis Track is based on the value matrix established within the context of architectural programming methodology and introduced within the theoretical background (Table 1). For each of the 12 proposed conceptual models, a critical analysis of programming values was conducted. It was performed through identifying their relevance/irrelevance for the perspective development or identifying a particular value as a concept generator for the reprogramming process.

The Multiscale Analysis Track is based on the relevant spatial levels for modernist architecture heritage and specific typo-morphological framework of engaged case study: (1) activity setting (the proximate environment in which behavior occurs), (2) single spatial unit/room (an assembly of activity/behavior settings), (3) building (an assembly of spatial units or rooms), (4) block (a complex of buildings), (5) community (an assembly of city blocks or neighborhoods) and (5) region/landscape (an assembly of communities at the geographic scale). For each of the 12 proposed conceptual models, a critical analysis of spatial levels was conducted by identifying their influence/neutrality for the perspective development or identifying a particular spatial focus for concept development.

After value-based and multiscale analysis, an analysis of the types of the architectural program was conducted in line with the three relationships: (1) hybrid relations of program elements, (2) relation of program and form and (3) relations of functions (functional performance of space) (See Table 2). In the first step, the types of programs for each conceptual model are defined concerning the applied design strategy. In the next step, the conceptual models are clustered concerning the determinants of the architectural program.

\subsection{Case Study Area}

The choice of the modernist heritage case study was defined, having in mind the connection between modernist architectural doctrine and architectural programming. Modernist heritage enabled comparative research of programming values at different spatial levels - from the apartment unit to the community and regional level, both indoors and outdoors. In addition, such a choice of research area implied research in the local context as an essential aspect of a sustainable approach to heritage preservation and reuse.

The modernist housing urbanism and architecture of New Belgrade has become a representation of social, political, economic, demographic and cultural changes from socialist to capitalist policy [66]. This claim is supported by the fact that the socialist system enabled the systematic implementation of principles of the Congrès International $\mathrm{d}^{\prime}$ Architecture Moderne (CIAM) on a large urban scale, in contrast to capitalist countries where these principles were applied on a smaller scale [67]. Such large urban areas built according to the principles of modernism are very rare because of the above-mentioned reasons. In addition, this is especially interesting in the context of modernist architecture of New Belgrade heritage status. Jovanovic-Nenadovic states that the formation of a new, socialist state in the post-war atmosphere of collectivism, supported by the desire for a better future and the need for new housing, conditioned the adoption of modernism as a mandatory content of social reform and a logical "tool of expression" of the moment [68].

In the last few decades, during the transition period, the urban transformation of New Belgrade is predominantly manifested as a densification through the usurpation of free green spaces between the buildings. Such changes have significantly impacted the structure of the users and quality of life in New Belgrade, particularly in terms of 
functional complementarity, which has enabled sustainable transport and a reduction in the space-time fragmentation of human needs (accommodation, work, leisure time) [69].

The Genex Tower-Western City Gate was chosen as a specific location for the architectural intervention (Figure 1). As an iconic modernist structure, Genex Tower represents a valuable and interesting polygon for reexamining the attitudes towards the architectural heritage, particularly modernist heritage. The Western City Gate represents a symbol, a gate that greets visitors upon their arrival to Belgrade from the west. It is located near the highway leading from the Belgrade Nikola Tesla Airport to the city of Belgrade. The building is actually a complex of two towers connected by a top restaurant bridge. The smaller tower (26 floors) was owned by the leading Yugoslav trade firm, General Export Company, which is why the structure is usually called Genex Tower. As a symbol of the technological progressiveness of socialist society, the restaurant on the top was initially planned as revolving, but it never functioned as such. It was built within the modernist housing urban context. Block 1 in the immediate context is the first residential block built in New Belgrade. Residential blocks 1 and 2 were designed from 1958 to 1959 and realized from 1959 to 1963. The ideology of the Modern Movement in the newly designed Belgrade settlement was promoted through the vision of a new, clean and healthy city and the application of new, modern technologies. The basic structural model of the concept of a functional city in the newly designed settlements was an open block with independent buildings surrounded by greenery [12].

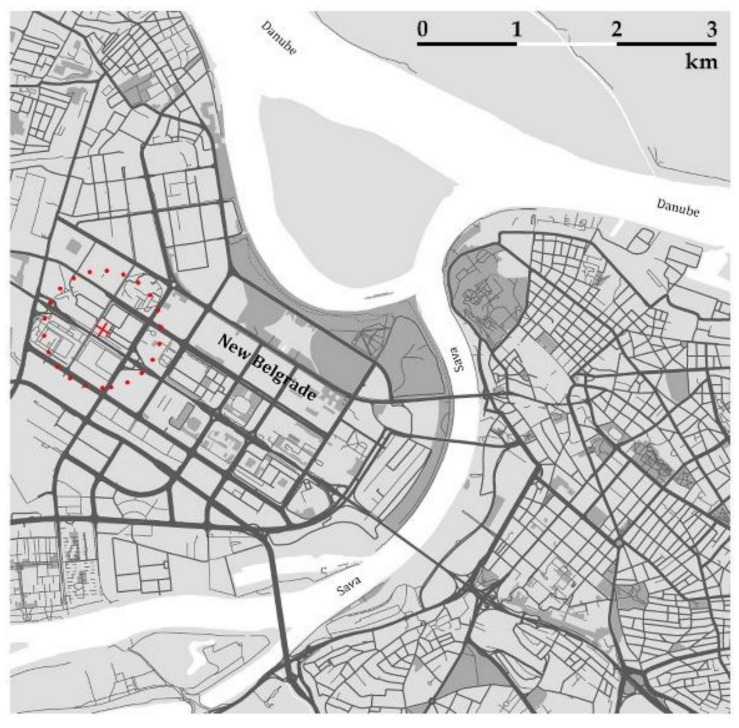

(a)

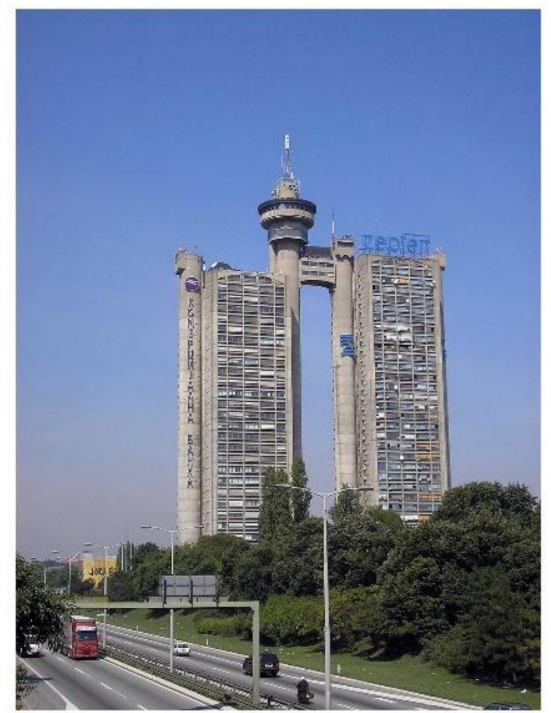

(b)

Figure 1. Genex Tower-Western City Gate: (a) location within a broader city context, source: authors; (b) photo from the highway, source: Michael Angelkovich, distributed under a CC BY-SA 3.0 license.

Genex Tower was designed in the 1970s by the architect Mihajlo Mitrović within the modernist urban housing context. However, the building itself is on the very border of the transition from modernism to postmodernism. The main exceptional feature of the building is the fact that it is a combination of work and residence. With the final triumph of private property and the bankruptcy of the company Genex, the business tower lost its original use-value. Its twin, the residential tower, is still in use, but with obvious problems in meeting the contemporary users' needs and the contested value of living standards due to these problems. Permanently changing ideological influences have generated new values and requirements related to the heritage and have established new challenges in its preservation and plans for future use. In line with that, Genex Tower is extremely interesting as a case study due to the multiple dichotomies, opposites and boundary fields that characterize it. 


\section{Findings and Discussion}

The discussion and results will be presented in accordance with the knowledge gained in different research phases: (a) the developed conceptual models, (b) multiscale and value-based heritage programming perspectives and (c) clustering the conceptual models concerning the architectural program types. The first part will be discussed by presenting 12 conceptual models explaining identified perspectives in line with programming values and relevant spatial levels (scales) and by identifying targeted social dimensions of wellbeing and the specificity of applied architectural program characteristics. The second part of the discussion has a systematizing and synthesizing character, and it is multi-comparative in nature in order to propose a universal agenda for heritage reprogramming. The third part of the discussion focuses on the clustering of conceptual models concerning the determinants of the architectural program and their applicability on different spatial levels.

\subsection{Reprogramming Modernist Heritage in Line with Social Wellbeing}

A discussion of the developed conceptual models for reprogramming modernist architecture heritage will be built concerning the five central elements of the programming information matrix. Previous research indicates that defining the architectural program is achieved exclusively by considering all the elements of the information matrix. In this regard, the explication of each of the 12 conceptual models (see Figure 2 and Table 3) will include the consideration of the following elements [43]: (a) concept (values particular emphasis, general idea), (b) need (motivation for conceptual model generation), (c) problems (gaps in a contemporary moment), (d) facts (contextual features) and (e) goals (in line with the social dimension of heritage).
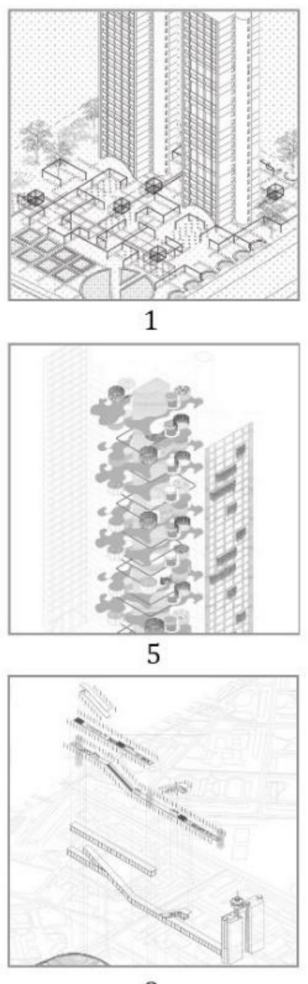

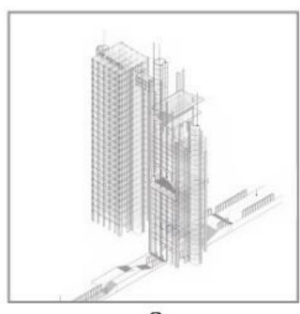

2

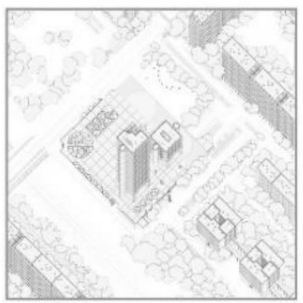

6

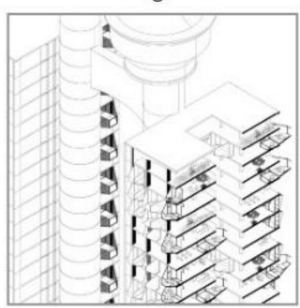

10

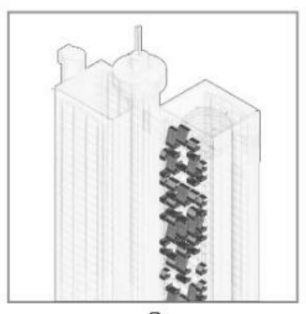

3

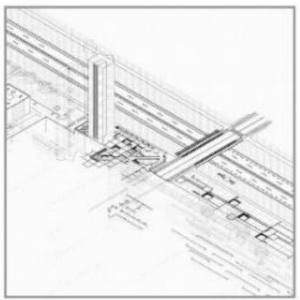

7

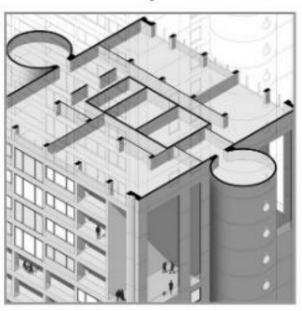

11

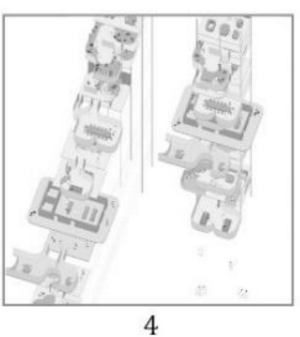

4
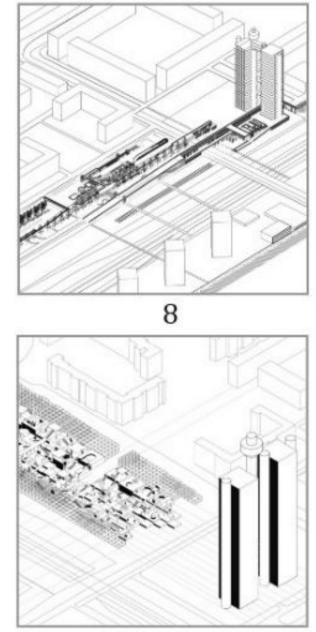

12

Figure 2. Conceptual models illustrations: (1) Sofija Sinobad, (2) Una Obradović, (3) Danica Petrović, (4) Dunja Dedić, (5) Milica Mijajović, (6) Nenad Pavlović, (7) Andrej Jovanović, (8) Katarina Spasojević, (9) Jovana Prijović, (10) Teodora Stevanović, (11) Mihailo Milosavljević, (12) Milica Knežević. 
Table 3. Overview of 12 conceptual models.

\begin{tabular}{|c|c|c|c|}
\hline $\begin{array}{l}\text { Conceptual } \\
\text { Model }\end{array}$ & $\begin{array}{l}\text { Aim/Reprogramming } \\
\text { Perspective }\end{array}$ & $\begin{array}{l}\text { Desired Social Wellbeing } \\
\text { Outcome }\end{array}$ & Key Words/Notions \\
\hline 1 & $\begin{array}{c}\text { Urban Practices of Everyday } \\
\text { Life }\end{array}$ & $\begin{array}{l}\text { Enhancing Access to } \\
\text { Education }\end{array}$ & $\begin{array}{l}\text { active social engagement } \\
\text { educational mediums } \\
\text { learning }\end{array}$ \\
\hline 2 & Urban Commons & $\begin{array}{c}\text { Enhancing Participation in } \\
\text { Political Life }\end{array}$ & $\begin{array}{l}\text { political institutions } \\
\text { place of cultural expression } \\
\text { creating a new culture }\end{array}$ \\
\hline 3 & Modernist Housing & Enhancing Living Standards & $\begin{array}{l}\text { housing culturenew ways of } \\
\text { living and leisure } \\
\text { dwelling activities }\end{array}$ \\
\hline 4 & Leisure Time & $\begin{array}{l}\text { Enhancing Spiritual } \\
\text { Fulfilment }\end{array}$ & $\begin{array}{l}\text { dichotomy of working-living } \\
\text { antithesis of capitalism } \\
\text { sequences of space }\end{array}$ \\
\hline 5 & Urban Nature & Enhancing the State of Health & $\begin{array}{c}\text { heritage in harmony with nature } \\
\text { health of residents } \\
\text { biological diversity }\end{array}$ \\
\hline 6 & Urban Economy & Enhancing Economic Security & $\begin{array}{c}\text { circularity of heritage } \\
\text { prefabrication and modularity } \\
\text { economic aspects of rehabilitation }\end{array}$ \\
\hline 7 & Collective Memory & $\begin{array}{c}\text { Enhancing Attachment to } \\
\text { Place }\end{array}$ & $\begin{array}{l}\text { heritage as an inseparable whole } \\
\text { preservation of memories } \\
\text { story of the city }\end{array}$ \\
\hline 8 & Urban Mobility & $\begin{array}{l}\text { Enhancing Access to } \\
\text { Community Resources }\end{array}$ & $\begin{array}{l}\text { mobility for social groups } \\
\text { diversity of common spaces } \\
\text { social dimensions of life }\end{array}$ \\
\hline 9 & Urban Recreation & Reducing Level of Stressors & $\begin{array}{c}\text { urban recreation } \\
\text { interaction of citizens with nature } \\
\text { natural environments }\end{array}$ \\
\hline 10 & Proxemic & $\begin{array}{c}\text { Enhancing Pleasantness and } \\
\text { Safety of Physical } \\
\text { Environments }\end{array}$ & $\begin{array}{l}\text { spatial and social distancing } \\
\text { personal and common space } \\
\text { flexibility and transformability }\end{array}$ \\
\hline 11 & $\begin{array}{c}\text { Architectural Tourism } \\
\text { Scenarios in the Modernist } \\
\text { City }\end{array}$ & $\begin{array}{l}\text { Enhancing Cultural Diversity } \\
\text { and Social Acceptance }\end{array}$ & $\begin{array}{l}\text { tourist potentials of heritage } \\
\text { presentation of heritage } \\
\text { urban exploration and cultural practice }\end{array}$ \\
\hline 12 & Public Space & $\begin{array}{l}\text { Enhancing Community } \\
\text { Connections }\end{array}$ & $\begin{array}{l}\text { holistic public spaces } \\
\text { modular environments } \\
\text { system of social interactions }\end{array}$ \\
\hline
\end{tabular}

4.1.1. Conceptual Model 1: Reprogramming Urban Practices of Everyday Life-Enhancing Access to Education

Conceptual model 1 focuses on reprogramming the urban practices of everyday life, describing the tactics available to the common man for reclaiming his autonomy from the all-pervasive forces of commerce, politics and culture [70]. It develops the concept of an urban laboratory with a particular emphasis on the research and implementation of social (cultural and common), systemic (technologies and processes) and temporal (change) programming values and indicators. Based on a comparative analysis of original drawings and plans dating from the 1950s and the contemporary concept of public spaces, it develops the system of spaces programmatically connected with various urban practices in the context of New Belgrade, especially from the aspect of their presentation and the possibility of active social engagement. This design strategy has a capacity to develop different educational mediums and encourage not only learning about modernist heritage and its 
transformation processes but also active participation in these processes. Transformable structures and technologies are distinguishing factors of the physical feature that enables constant change and adoption of the program in line with different urban practices of everyday life and different intentions and needs of laboratory users. In this way, public space in the city becomes a place of education and action regarding understanding and preserving the heritage.

The nature of this architectural program, which aims to enhance access to education, is primarily characterized by the dependence between singular parts (modular units) through their interaction based on the singleness of function between the various assembled elements. Accordingly, each spatial unit has specific educational content related to the inherited space - active education/learning and the heritage representation/exhibition spaces. The spatial concept results in a fragmented form added as an exoskeleton to the existing spatial framework. At the same time, the program is thematic according to the hybrid relations of program elements. Considering the types of architectural programs from the aspect of the program-form relationship, Conceptual Model 1 is characterized by indifference. The existing spatial framework of the Genex tower acquires a completely new educational content while retaining a deterministic form. Added fragmented units have the role of enhancing access to education. Concerning the broader context of the territory of New Belgrade within which the case study is located, and which is characterized by dominant residence function, the design strategy of this Conceptual Model is aimed at creating a spontaneous program in accordance with functional performance relations, which implies physically porous spaces with variable educational activities directed towards reprogramming urban practices of everyday life.

4.1.2. Conceptual Model 2: Reprogramming Urban Commons-Enhancing Participation in Political Life

This conceptual model questions the survival of formal political institutions and their impact on people's lives. New Belgrade was developed under socialist ideology and strong political institutions with specific spatial and organizational logic [71]. However, today, there is an evident problem regarding the ownership, maintenance and protection of this heritage. The design research is emphasized on the public space within the urban block as a public commons of particular importance for the overall welfare and wellbeing of the community, especially having in mind the inadequate and irregular urban practices in these areas today. Through the reprogramming of the urban commons, the Genex Tower was reprogrammed into an institution becoming a "stage" that offers back the public right to engage around issues of their environment, calls for debates, conflicts and the promotion of values. It creates multiple options which enable the interaction between people and space. In this way, as a place of cultural significance, the Genex Tower receives the capacity to become a place of cultural expression. The conceptual model is based on a range of programming values relevant for this subject, with emphasis on environmental (regional context), human (psychological), social (legal and common) and temporal (change) programming values and indicators. The result is an architectural program that enables citizens to be engaged in political life by creating a new culture in the broadest possible sense.

The nature of the architectural program focused on enhancing the participation in political life is based primarily on thematic hybridity, characterized by the dependence between interior and exterior parts of the building and encouraging the interaction inbetween public space and Genex Tower. Conceptual Model 2 engages a design strategy of the fragmentation of a form, i.e., the decomposition of its segments, in order to achieve a high degree of interactivity between public space as a place of cultural expression and the Genex Tower building as a place of cultural production. In this sense, program and form are reciprocal-form is shaped to reciprocate the configuration assigned to the program, which is directed towards the wider community. According to functional performance, the architectural program is spontaneous (soft), described as physically porous spaces involving variable activities for citizens' political engagement, which is a consequence of 
the decomposition of certain parts of the inherited space. It is essential to point out that such a program strategy does not disrupt the silhouette and architectonics of the building.

\subsubsection{Conceptual Model 3: Reprogramming Modernist Housing_Enhancing Living Standards}

Conceptual model 3 starts from housing culture as one of the most recognized values of the modernist heritage of New Belgrade. The period of intensive housing construction of New Belgrade within the socialist self-management system is primarily related to the achieved housing quality in terms of environmental humanization and functional organization of housing units $[69,71]$. Regardless of the recognized qualities and characteristics of the Belgrade school of housing, traditionally designed housing patterns, contents and structures cannot meet many of the current needs of life and leisure culture. The conceptual model goal is to reconsider new ways of living and leisure adapted to contemporary man and reconsider the position of work and education in contemporary urban housing, especially considering continuous change and unexpected circumstances such as the pandemic. Accordingly, the focus is on human (psychological and functional), social (cultural and common) and aesthetic (change) programming values and indicators, and many other values considering the complexity of the housing issue. In terms of the physical framework of the model, reprogrammed housing units are designed as flexible with different common spaces within the common area of the building that can support a wide range of dwelling and leisure activities. The concept is based on the good modernist tradition but interpreted in a contemporary manner as a juxtaposition between residency, work, education and recreation. The main aim is to understand whether and how to preserve the sustainability of life within the modernist heritage and how reprogrammed urban housing can become a valuable agent of socialization in the process of urban regeneration.

Enhancing living standards implies a particular challenge in the context of modernist residential architecture that emerged as a result of deterministic nomenclature and standardization of living space. In this sense, reprogramming strategies are reflected in bridging the gap between mono-functionality (a prescriptive program of the inherited residential part of Genex Tower) and new contents that can generate added value and reach the contemporary standard of living spaces. Accordingly, the nature of the architectural program directed towards the enhancement of living standards is based primarily on disparate hybridity-characterized by the pursuit of economic benefits. Adding contents for leisure culture affirmation within the existing housing units results in unexpected functional configurations. In terms of functional performance of the architectural program, Conceptual Model 3 combines prescriptive and spontaneous programs to create a balance in newly defined functional configurations. Prescriptive programs refer to the inherited functional order of residential units within the Genex Tower. In contrast, spontaneous programs refer to the new contents of contemporary everyday life that are implemented within the existing inherited framework. Although this conceptual model combines several types of architectural programs in accordance with the functional performance and that a conflict in such relations could be expected, it is indifferent, resulting in the preservation of the existing deterministic form and an indeterminate program.

\subsubsection{Conceptual Model 4: Reprogramming Leisure Time-Enhancing Spiritual Fulfilment}

The outcome of this reprogramming perspective is a conceptual model that questions attitudes towards the architectural heritage based on the observation of the building predominantly as an iconic material structure. Starting from the attitude that the architectural structure lives as long as it is actively used, as long as it is full of city noise and does not represent an exclusively frozen artefact of the past, this conceptual model deals with leisure culture due to the already inscribed dichotomy working-living, i.e., work-leisure time. Such a reprogramming framework enables that the image of the city remains the same but is changed in a narrative manner. This subject engages with in-depth reprogramming of environmental (climatic), human (psychological), social (cultural and common) and aesthetic (space) programming values and indicators as particular concept generators. An 
eclectic program builds a link between the past and the present. The new leisure regime is the antithesis of capitalism. By interpreting the characteristic spatial elements, new ones are created, which build an image within an image. Through different ambiences, sequences of space and microclimates, the reinterpretation of the traditional public bathroom contrasted with the working space builds a new narrative of modern leisure culture, implying spiritual and cultural cleansing and a much-needed spiritual fulfilment of the contemporary citizen. Unlike the contemporary globalist spectacle of free time, it nurtures taken but deeply grounded traditions and places them in a new context. Genex Tower becomes a place to stimulate senses, a place of overemphasized reality, a point that generates the program in creating a flexible space.

The nature of the architectural program, which deals with enhancing spiritual fulfilment, is based on the cross-implementation of thematic and disparate hybridity. Thematic hybridity of the program implies dependence between different sequences of space towards the fragmentation of a form, while disparate hybridity of the program implies adding non-complementary functions to the existing architectural framework, which add value to the working-living dichotomy. Such a dichotomy most often results in a flexible space designed to engage different regimes and scenarios of space use that are often noncomplementary to the primary function. Accordingly, the relationship between program and form within Conceptual Model 4 is conflict, which implies that programs and forms intentionally collide in order to generate unexpected events in space. Keeping in mind that spiritual fulfilment enhancement requires a high level of responsivity to users' environmental conditions and behavioral possibilities, the functional performance of the program within Conceptual Model 4 is spontaneous (soft). It involves physically porous spaces with variable activities for leisure-time fulfilment.

\subsubsection{Conceptual Model 5: Reprogramming Urban Nature-Enhancing State of Health}

This conceptual model focuses on the reprogramming of modern heritage in harmony with nature. It starts from the traditionally developed relationship between modern architecture and nature, primarily from the aspect of big greenery spaces in-between buildings introduced to improve hygienic conditions and the health of residents. The decoding of programming values resulted in the conclusion that contemporary culture requires much closer contact with nature, primarily in terms of its integration with the built environment and blurring the boundaries between architecture and nature. The intrinsic value of biological diversity, as well as the ecological, genetic, social, economic, scientific, educational, cultural, recreational and aesthetic values of biological diversity and its critical role in maintaining ecosystems that provide essential services, represent critical foundations for sustainable development and human wellbeing [41]. Reprogramming values and indicators that were crucial in terms of concept generation were environmental (climate), human (psychological), social (cultural and common), systemic (technologies) and aesthetic (tradition). This model deals with the concept of biophilia, which advocates an innate connection between humans and nature. Scientific studies have pointed out a multiplicity of benefits of nature for people, especially for children and older populations. People tend to show a positive response when they experience a connection with nature [72]. When most cities suffer from health and environmental problems, enhancing the wellbeing and health of citizens is one of the urgent urban issues.

The nature of the architectural program built on the tendency to enhance health is thematic and based on the dependence between single spatial units or elements that bring benefits of nature and ecology for users. Creating a sustainable configuration of architecture and nature is the primary goal of this design strategy directed towards reprogramming urban nature. In the context of the relationship between program and form, the main goal in the design process is to achieve reciprocity. From an exterior aspect, the original form of Genex Tower is fully preserved. At the same time, interior space reciprocates the configuration assigned to the program by implementing a series of program scenarios that improve hygienic conditions and user health. Consistent with the concept of biophilia and 
the multiple benefits provided by ecosystem services at the interior level, the functional performances of the program in Conceptual Model 5 are spontaneous (soft) and create blurred boundaries between architecture and nature. In the context of architectural heritage, the introduction of nature through a spontaneous (soft) program also enables a high level of environmental sensitivity.

\subsubsection{Conceptual Model 6: Reprogramming Urban Economy_Enhancing Economic Security}

This conceptual model starts from the premise that due to changing the socioeconomic milieu, mainly due to the transition from socialism to capitalism, the heritage becomes intensely subjected to the norms of globalization. This premise generated a new look at the circularity of heritage, observing deterioration as an integral part of the architectural structure's life. Through the decoding of particularly social (cultural and legal), systemic (processes) and economical (operationalization and maintenance) programming values and indicators, this concept develops a critical and, at the same time, provocative approach to modernist heritage. The physical framework of the model is challenged by structural characteristics and durability, methods of prefabrication and its characteristics, as well as economic aspects of rehabilitation that jointly argue and illustrate the circularity of the concept. The process of decomposing the existing building and extending it through the life of individual prefabricated parts lies in the spirit of the modernist architecture tradition based on prefabrication and modularity. In this way, time is the generator of myth, forming a narrative that will outlive it.

The nature of this architectural program built on the aspiration to enhance economic security is characterized by both thematic and disparate hybridity in accordance with the experimental nature of Conceptual Model 6, which affirms the idea of circularity and the reconfiguration of Genex Tower into a series of new typologies. In this case, the disparate program is defined by new typologies/spatial entities that are built using the structural elements of Genex Tower, while the thematic program is defined by its singleness of function between the various assembled elements. A specific economic benefit that engages the reuse of materials and structural elements is achieved as the overall outcome of the spatial structure reconfiguration. Accordingly, the relationship between program and form within Conceptual Model 6 is reciprocal, which means reconfiguring the form to reciprocate the configuration assigned to the program. At the level of the architectural program's relation to functional performance, this conceptual model has twofold orientation-both prescriptive (hard) and spontaneous (soft). The prescriptive nature of the program is recognized at the spatial level of the activity setting and the single spatial unit/room. It implies fixed spaces necessary for basic operation and servicing. In contrast, the spontaneous nature of the program is recognized at the spatial level of the region/landscape. It implies a heterogeneous distribution of new typologies created by the reconfiguration of inherited spatial structure.

\subsubsection{Conceptual Model 7: Reprogramming Collective Memory—Enhancing Attachment} to Place

Conceptual Model 7 views heritage as a very important element of our daily lives and quality of space in the level of intimacy between users and space. In order to know oneself, the heir must first (re)cognize the inheritance (endowment, bequest, ancestry) in order to understand its essence and the value of understanding what was before. Knowing the inherited, the heir is in a position to preserve it from oblivion, as well as to preserve the continuity of his own being. The significance of the Genex Tower is not seen as a completely isolated and segregated link, an isolated heritage monument, but as an inseparable whole not only within a narrower context or within the New Belgrade context but within the broader context of Belgrade city. In line with that, the environmental programming value (urban context) was one of the main concept generators, as well as social (cultural and common) and aesthetic values (style and tradition). Accordingly, this model considers heritage not only as a space for selected content but also as its content. In this way, it has the potential to provoke and intrigue visitors and to provide a special kind of education 
and preservation of memories (knowledge) of the past. The general idea of the model is to tell the story of the city, go into its secrets and show its foundations, discover the sand on which it lies and, like roots, encompass and preserve all stages of its development. In this way, the space of modernist heritage becomes (and remains) a place, a place with which the user identifies and to which he is attached.

The nature of the architectural program built on a tendency to enhance attachment to place is characterized by thematic hybridity. The thematic program, in this case, is defined by the dependence of Genex Tower and elements positioned in public space to represent the inherited collective memory and build a new one. Keeping in mind that the focus of the Conceptual Model 7 is on the block and community level, the relationship of the program and form is indifference and is primarily focused on open public space. Accordingly, the spatial framework of Genex Tower is fully preserved in its original form, while the implementation of a series of activities in public space affirms the attachment to place. Regarding the functional performance of the program, the creation of porous spaces in the immediate environment of Genex Tower enables involving variable activities focused on collective memory preservation.

\subsubsection{Conceptual Model 8: Reprogramming Urban Mobility-Enhancing Access to Community Resources}

When it comes to leisure culture, mass culture contributes to losing a specific cultural identity. This conceptual model focuses on the problem of urban transformation of New Belgrade due to appropriating the open public spaces between the blocks for new buildings. This negative trend is accompanied by the lack of activities, attractiveness and dynamics of public spaces and deviation from the principle of "man as the measure of all things". This conceptual model aims to give the individual, in addition to rest and leisure, the opportunity to nurture their personality and enhance the social dimensions of life through developed access to various community resources. The conceptual model advocates that improving mobility for social groups and diversity of common spaces encourages the further creation of additional diversity. In line with this idea, the particular concept generators are environmental (urban context), human (functional), social (cultural and common) and temporal (growth) programming values and indicators. Improving mobility encourages encounters, communication and exchange between users on an indirect and direct level. Intersections of the different flows and users generate "stages" that satisfy different social needs and leisure activities. "Stage" in this concept has two connotations, contextual, as a new typology created by various forms of human interaction, and formal, as a particular stage space, i.e., a place where plays, concerts, manifestations, etc., take place. In this way, the city is revived as a collective reality by rehabilitating the common spaces.

The nature of the architectural program built by enhancing access to community resources is characterized by thematic hybridity. The design strategy of Conceptual Model 8 is based on a system of flows and intersections that enable and improve access to various community resources. In that sense, the thematic program is manifested at the spatial level of the block and the community. It aims to encourage interaction in-between flows and nodes and the various public activities and contents. Such a framework further provides an opportunity to attract different user groups in line with seniority, gender, beliefs, hobbies and occupations. The relationship between the program and the form is reciprocal. The program adapts to the configurations of points and flows, i.e., the activities are grouped concerning the intersections and places of the highest concentration of users. In line with the functional performance, the program is spontaneous, involving variable activities which attract different user groups.

\subsubsection{Conceptual Model 9: Reprogramming Urban Recreation-Reducing Level of Stressors}

The construction of New Belgrade in the middle of the last century was characterized by transforming nature into an urban landscape. The "logic of domination" becomes especially recognizable in the previously deserted wetland refugee field, where the accelerated metabolic transformation of nature becomes most visible, both in physical form and in its 
socioecological consequences [12]. Today, New Belgrade's urban nature is particularly endangered, primarily due to densification and a poor attitude towards green areas. Through reprogramming urban recreation, this conceptual model has a capacity for improving the interaction of citizens with nature. Enhancing the concept of nature within the modernist city is founded on the possibilities of the transformation, expansion and improvement of environmental aspects of urban morphology, thus reconnecting people with nature. Programming values and indicators of particular importance for this concept are environmental (especially location and climate), human (psychological) and social (cultural and common), considering the importance of environmental issues, spiritual experience and individual as well as collective health and wellbeing. This model starts from the premise that it is essential to provide people opportunities to live and work in healthy places and spaces with less stress and greater overall health and wellbeing. In addition to nature's visual and aesthetic qualities in an urban environment, nature reduces stress, improves cognitive function and creativity, improves our wellbeing and expedites healing [72]. Nature has very characteristic complexity and order, so this conceptual model develops a specific system of natural environments and recreational spaces. Recreational contents are observed in the broadest sense of today's culture and enriched with content that encourages socializing and social contacts. Including rich sensory information in an urban environment that adheres to a spatial hierarchy similar to those found in nature resulted in enhancing overall health and reducing stress in the New Belgrade modernist environment.

The nature of the architectural program directed towards reducing the level of stressors is thematic according to hybrid relations of program elements. Considering that the reprogramming of urban recreation is carried out at the spatial level of block and community in direct correlation with the level of landscape/region, Conceptual Model 9 engages a systemic approach characterized by the dependence between single spatial elements and encouraging their interaction with nature. The design strategy is based on an environmentally sensitive approach in which the form is ephemeral and the program encourages socialization and social contacts through recreational content. On one side, such a strategy results in an indifferent relationship between program and form, while on the other, in line with the functional performance, it generates a framework for variable activities which encourage the interaction of citizens with nature and urban greenery.

4.1.10. Conceptual Model 10: Reprogramming Proxemics-Enhancing Pleasantness and Safety of Physical Environments

Preferred social, personal and intimate distances depend on users' individual characteristics and some attributes of their cultures. Proxemics are directly connected to how humans use space and the effects that population density has on behavior, communication, and social interaction. The COVID-19 pandemic and the demands for spatial and social distancing have raised a number of issues concerning architectural and urban design, especially from the aspect of dimensional analysis and established spatial relations and distances in space. These challenges are directly related to the harmonization of spatial and sociological levels within the "new reality", the possibility of flexibility and transformability in the context of changed relations between personal and common space and changes in traditionally adopted behavioral patterns. This conceptual model is one of the possible answers to how a pandemic can change urban and architectural space's understanding and spatial-program concepts. The main concept generators in proxemic reprogramming were human (physical), social (cultural and common), systemic (processes) and temporal (change) programming values and indicators. The application of contemporary technologies as a systemic process raises questions of defining new anthropometrical, dimensional and ergonomic aspects and the need to reconsider the pleasantness and safety of physical environments. The Modern movement in architecture started with Le Corbusier's premise that "a house is a machine for living in" [73]. This conceptual model examines the flexibility of spatial distances and levels through a design strategy that tends to a contemporary reinterpretation of the house as a living machine. 
The nature of the architectural program built by enhancing the pleasantness and safety of physical environments is characterized by the twofold hybridity of the programthematic and disparate. The thematic hybridity of the program implies dependence between a series of single spatial units of different dimensional and shape characteristics, resulting in the fragmentation of a form. The disparate hybridity of the program implies the creation of specific leisure and work contents that should economically strengthen the existing framework of the living space of Genex Tower. The design strategy of Conceptual Model 10 is based on the reconfiguration of the interior spatial structure of Genex Tower. The exterior architectonic and silhouette are preserved in the overall picture of the landscape/region. Reprogramming proxemics thus results in indifference between form and program - the form accommodates different arrangements of leisure and work contents resulting in the preservation of the existing deterministic form and an indeterminate program. The design outcome is reflected in improving the functional performativity of the space by complementing the existing residential framework in Genex Tower towards "the living machine". Conceptual Model 10 combines prescriptive and spontaneous programs to create a balance between inherited spatial framework and newly defined functional configurations. The prescriptive program refers to the functional order of the residential part of Genex Tower, while spontaneous programs refer to the new contents of contemporary everyday life that are implemented within the existing inherited framework.

4.1.11. Conceptual Model 11 Reprogramming Architectural Tourism Scenarios in the Modernist City_Enhancing Cultural Diversity and Social Acceptance

The emphasis of this conceptual model is on the tourist potentials of the modernist architecture of New Belgrade. Around the world, we can notice emerging practices of the "tourism of the ordinary" directed to the patterns of tourism consumption of practices, places and people that do not fall in the category of touristic attraction [74]. In this context, New Belgrade is slowly becoming explored by tourists individually or in organized walking or cycling tours. They are interested in principles of modernist architecture implemented on a large scale and the consequences of post-socialist transformation. The list of the most visited Belgrade museums shows that the memory of Yugoslavia is a significant tourist attraction. New Belgrade remains perhaps the best example of realized socialist utopia. Visits to New Belgrade represent an attraction for both urban exploration and cultural practice. This conceptual model starts from the premise that tourism promotion is sustainable to the extent that it produces not only economic impacts but also contributes to community wellbeing [40]. It re-examines these potentials through the authentic ambiences and activities of everyday life that marked socialist culture. In line with that, key concept generators are environmental (urban context), social (cultural and common), temporal (growth) and aesthetic (tradition) programming values and indicators. Preserving tangible and intangible heritage bounds all generations together, creating the unique essence and spirit of socialist society. Presenting the authentic nature of socialist culture through characteristic dwelling units of "Belgrade housing school" [71] enables tourists to experience this characteristic space and culture and at the same time to learn about one specific period and culture of living. In the context of mass tourism and globalization, the preservation and presentation of tangible and intangible heritage through the possibility of personal experience of these values play very important roles in the contexts of cultural tourism, and social dimension of heritage preservation, especially from the aspects of enhancing cultural diversity and social acceptance.

The nature of the architectural program focused on enhancing cultural diversity, and social acceptance is characterized by disparate hybridity, which is achieved by adding tourist facilities that increase the economic impact of the residential part of Genex Tower. In addition, thematic hybridity is recognized in line with the uniqueness of the tourismoriented function. Since the focus of Conceptual Model 11 is constituted by creating contemporary tourist regimes within modernist residential areas, the basic design strategy aims to create different typologies of housing units that can respond to the needs of different user groups in the context of the city as a tourist polygon. The relationship 
between form and program is indifference. This relationship is a consequence of the design intention to preserve the existing spatial framework both at the level of exterior and interior and to establish new functional order. Conceptual Model 11 combines prescriptive and spontaneous programs to create a balance between inherited residential framework and newly defined tourist function. The prescriptive program refers to the fitting of tourist functions into the existing physical framework and building services. Spontaneous programs refer to the affirmation of new contents and activities of contemporary tourism resulting in the reconfiguration of existing inherited framework.

\subsubsection{Conceptual Model 12: Reprogramming Public Space-Enhancing Community Connections}

Bearing in mind that the change of state system and dominant social goals in $\mathrm{Yu}-$ goslavia after the Second World War conditioned radical transformations of urban life, architecture was required to have a new concept of housing estates in accordance with the mentioned principles of creating a new socialist society [12]. The basic structural model of the modernist city concept in the newly designed settlements was an open block with independent buildings surrounded by greenery. The focus was on a healthier environment, a large open public space and opportunities for active recreation. However, the insistence on large dimensions in modernism resulted in a loss of humanity, a disturbance of environmental perception and a lack of social interactions and identification with the settlement $[12,75,76]$. Accordingly, this conceptual model advocates a "shredding" approach through the design of modular, holistic public spaces. Modular environments have the capacity to accommodate different activities. Therefore, the concept is based on a complex, comprehensive and interdependent system of social interactions. The main concept generators are environmental (urban context), social (cultural and common), temporal (growth) and aesthetic (tradition) programming values and indicators. In this way, the model affirms at the same time continuous interaction between users mutually but also their interaction with the environment, producing new forms of social interaction and new spatial relations. The result is the architecture of relations. In addition, the experience of space is perceived as a direct connection with social dimensions of space and the intensity of social interactions.

The nature of the architectural program directed toward enhancing community connections is characterized by thematic hybridity. The design strategy of Conceptual Model 12 is based on the fragmentation of public space and the singleness of function between the various assembled elements, which define the comprehensive form of public space through repetition. The focal spatial levels of this model are block and community with the primary intention of networking with a broader context and public spaces in the immediate environment. The relationship of form and program is indifference, resulting from the design intention to enhance community connections through developing a framework for enhancing place attachment to Genex Tower. Accordingly, the focus of the architectural intervention is within the unbuilt spatial framework opposite to Genex Tower. In line with the functional performance, the program is spontaneous, involving variable activities that attract different user groups and provide polygon for diverse activities.

\subsection{Multiscale and Value-Based Heritage Reprogramming Perspectives}

This part of the findings and discussion tends to establish an argumentative mapping of the presented conceptual models in relation to the value-based approach in architectural programming and a multiscale approach for the purpose of decoding a particular spatial focus of conceptual model development. By the nature of the discussion, it is cross-cutting, considering 12 conceptual models, first with programming values (value track) and then with spatial level (scales) references for modernist architecture (multiscale track).

Insight into the value track analysis (Table 4) — conducted by identifying their relevance/irrelevance for perspective development or by identifying a particular value as a concept generator for reprogramming - primarily recognizes the capacity of the methodological programming framework to be an assessment tool for the valorization and concep- 
tual foundation for architectural heritage reprogramming. First of all, it is recognized that the specific framework of conceptual models in line with the social dimensions of wellbeing has completely different value indices, i.e., none of the 12 identified conceptual models contain an identical relationship of particular concept generator with other value factors. Such a finding is a direct indicator that the matrix of values for reprogramming cannot be established at the universal and general level but that the relevant values can be identified concerning the conceptual idea, motivation, identified gaps for bridging or potentials for enhancement, contextual features as well as the social dimension of heritage. This interpretation can also be related to the type of heritage that is the subject of reprogramming. Accordingly, this research illustrates value-based architectural programming potential for creating different conceptual models for achieving various social wellbeing dimensions.

Table 4. Identification of relevant programming values.

\begin{tabular}{|c|c|c|c|c|c|c|c|c|c|c|c|c|c|}
\hline \multirow{2}{*}{$\begin{array}{l}\text { Programming } \\
\text { Values }\end{array}$} & \multirow{2}{*}{$\begin{array}{l}\text { Programming } \\
\text { Indicators }\end{array}$} & \multicolumn{12}{|c|}{ Conceptual Model } \\
\hline & & 1 & 2 & 3 & 4 & 5 & 6 & 7 & 8 & 9 & 0 & 11 & 12 \\
\hline \multirow{4}{*}{ environmental } & \multirow{4}{*}{$\begin{array}{c}\text { location } \\
\text { climate } \\
\text { urban context } \\
\text { regional context }\end{array}$} & + & + & + & + & + & + & + & + & $\bullet$ & + & + & + \\
\hline & & $x$ & $x$ & $x$ & $\bullet$ & $\bullet$ & $x$ & $x$ & $x$ & $\bullet$ & $x$ & $x$ & $x$ \\
\hline & & + & + & + & + & + & + & $\bullet$ & $\bullet$ & + & + & $\bullet$ & $\bullet$ \\
\hline & & $x$ & $\bullet$ & + & $x$ & $x$ & $x$ & + & $x$ & + & $x$ & + & + \\
\hline \multirow{4}{*}{ human } & \multirow{4}{*}{$\begin{array}{c}\text { physical } \\
\text { physiological } \\
\text { psychological } \\
\text { functional }\end{array}$} & $x$ & + & + & + & + & + & $x$ & + & + & $\bullet$ & + & + \\
\hline & & $x$ & + & + & + & + & $x$ & $x$ & + & + & + & + & $\mathrm{x}$ \\
\hline & & + & $\bullet$ & $\bullet$ & $\bullet$ & + & $x$ & + & + & $\bullet$ & + & + & + \\
\hline & & + & + & $\bullet$ & + & + & + & + & $\bullet$ & + & + & + & + \\
\hline \multirow{3}{*}{ social } & cultural & $\bullet$ & + & $\bullet$ & $\bullet$ & $\bullet$ & $\bullet$ & $\bullet$ & $\bullet$ & $\bullet$ & $\bullet$ & $\bullet$ & $\bullet$ \\
\hline & legal & + & $\bullet$ & + & + & + & $\bullet$ & + & + & + & + & + & + \\
\hline & common & $\bullet$ & $\bullet$ & $\bullet$ & $\bullet$ & $\bullet$ & + & $\bullet$ & $\bullet$ & $\bullet$ & $\bullet$ & $\bullet$ & $\bullet$ \\
\hline \multirow{3}{*}{ systemic } & \multirow{3}{*}{$\begin{array}{c}\text { materials } \\
\text { technologies } \\
\text { processes }\end{array}$} & + & $x$ & $x$ & + & + & + & + & $x$ & $x$ & $x$ & $x$ & $x$ \\
\hline & & $\bullet$ & $x$ & $x$ & + & $\bullet$ & + & + & $x$ & $x$ & + & $x$ & $\mathrm{x}$ \\
\hline & & $\bullet$ & $x$ & $x$ & + & + & $\bullet$ & + & + & + & $\bullet$ & $x$ & + \\
\hline \multirow{3}{*}{ temporal } & \multirow{3}{*}{$\begin{array}{l}\text { growth } \\
\text { change } \\
\text { constancy }\end{array}$} & + & + & $x$ & $x$ & + & + & $x$ & $\bullet$ & $x$ & + & $x$ & $\bullet$ \\
\hline & & $\bullet$ & $\bullet$ & + & + & + & + & + & + & + & $\bullet$ & + & + \\
\hline & & $x$ & $x$ & $x$ & $x$ & $x$ & $x$ & $x$ & $x$ & $x$ & $x$ & $x$ & $x$ \\
\hline \multirow{3}{*}{ economic } & \multirow{3}{*}{$\begin{array}{l}\text { building costs } \\
\text { operationalization } \\
\text { maintenance }\end{array}$} & + & + & + & $x$ & $x$ & + & $x$ & $x$ & $x$ & $x$ & $x$ & $\mathrm{x}$ \\
\hline & & + & + & + & $x$ & $x$ & $\bullet$ & $x$ & $x$ & $x$ & + & $x$ & $x$ \\
\hline & & + & + & + & $x$ & $x$ & $\bullet$ & $x$ & $x$ & + & $x$ & $x$ & $x$ \\
\hline \multirow{4}{*}{ aesthetic } & form & + & $x$ & + & + & + & + & + & + & + & + & + & + \\
\hline & space & + & $x$ & + & $\bullet$ & + & + & + & + & + & + & + & + \\
\hline & style & $x$ & + & + & + & + & $x$ & $\bullet$ & + & + & + & $\bullet$ & + \\
\hline & tradition & + & + & $\bullet$ & $\bullet$ & $\bullet$ & $x$ & $\bullet$ & + & + & + & $\bullet$ & $\bullet$ \\
\hline
\end{tabular}

Index: $\mathrm{x}$-irrelevant; +—relevant; •-particular concept generator.

Observing the distribution of indicators denoting particular concept generators, it is recognized that all conceptual models have a focus on generating concepts within social values (cultural, legal, common). All conceptual models have two values within the social category that open perspectives for reprogramming. The emphasis is primarily on cultural and common values, while legal values are consistently recognized as relevant. In addition, it is recognized that all conceptual models include additional particular concept generators in other value categories, which indicates the need to holistically view all value categories and consider them as a critical framework for design. This also confirms that values should be identified in a synergy of different contextual factors and indicators.

Insight into the multiscale track analysis (Table 5) — conducted by identifying the influence/neutrality of particular scale (spatial level) for perspective development or by identifying a particular spatial focus for concept development-confirms the multiscale approach as a leading prospectus for achieving a reflexive dialogue between heritage and 
contemporary architecture. Findings point out that heritage entities should be understood in their broader context in order to argumentatively establish a value framework in line with the critical urban environment. As a case of value-based analysis, it is recognized that the specific framework of conceptual models in line with the spatial levels has completely different value indices, i.e., none of the 12 identified conceptual models contain an identical relationship of particular spatial focus with other value factors. Particular spatial focus is primarily assigned concerning the user-environment-behavior relations and the degree of spatial dependence concerning sociological levels.

Table 5. Identification of relevant spatial levels for reprograming.

\begin{tabular}{|c|c|c|c|c|c|c|c|c|c|c|c|c|}
\hline \multirow{2}{*}{ Spatial Level } & \multicolumn{12}{|c|}{ Conceptual Model } \\
\hline & 1 & 2 & 3 & 4 & 5 & 6 & 7 & 8 & 9 & 10 & 11 & 12 \\
\hline activity setting & + & $x$ & $\bullet$ & • & + & $x$ & $\bullet$ & • & + & • & + & • \\
\hline $\begin{array}{l}\text { single spatial } \\
\text { unit/room }\end{array}$ & • & + & $\bullet$ & + & $\bullet$ & + & + & $x$ & $x$ & $\bullet$ & $\bullet$ & $\mathrm{x}$ \\
\hline building & $\bullet$ & $\bullet$ & + & $\bullet$ & $\bullet$ & + & + & + & + & $\bullet$ & $\bullet$ & + \\
\hline block & + & + & + & + & $\bullet$ & $\bullet$ & $\bullet$ & $\bullet$ & $\bullet$ & + & + & $\bullet$ \\
\hline community & + & + & $x$ & $x$ & + & $\bullet$ & $\bullet$ & $\bullet$ & $\bullet$ & $x$ & • & $\bullet$ \\
\hline region/landscape & $x$ & $\bullet$ & $x$ & $x$ & + & $\bullet$ & + & + & - & $x$ & $\bullet$ & + \\
\hline
\end{tabular}

Observing the distribution of indices denoting a particular spatial focus, it is recognized that all conceptual models have a focus on generating concepts within the building and block level. On the other hand, it is recognized that each of the 12 conceptual models contains a particular spatial focus on one of the higher or lower spatial scales. Such values confirm the thesis that architecture is a complex systemic construct reflected in a different hierarchical order. Decoding the architectural heritage values contains a broader contextual background and factors in relation to the primary scale of the architectural intervention.

The results have shown that the multidimensional nature of the architectural programming methodological approach in the context of modernist heritage and, accordingly, the synergy of different programming values (environmental, human, social, systemic, temporal, economic, aesthetic) provides sustainable access to heritage and has the capacity to improve the social wellbeing of individual users but also the wider community.

The evaluation of the results thus indicates the possibility of improving the social dimension of heritage protection and reuse, as well as the need to shift the focus from exclusively material and formal values of heritage towards social and cultural aspects in accordance with the contemporary society and culture needs. The value-based architectural programming approach is based on the adaptive logic of architectural practice. It reveals the possibilities of transformation, expansion and improvement of aspects of wellbeing in the built and natural environment through a sensitive attitude towards inherited values, which intensifies user-heritage relations. Traditional architectural approaches to heritage are generally limited to considering only certain aspects and values, not taking into account the complexity and indissolubility of all aspects and especially the relation of social aspects and values with other values. In addition, the evaluation confirmed the multiscale nature of this approach and the possibility of targeting different spatial dimensions: from an individual ambience to entire culturally inherited landscapes.

Accordingly, the value-based approach of architectural programming presupposes the establishment of a sensitive relationship with the specific climatic-ecological, social and cultural context and implies the enhancement of various social wellbeing dimensions. 


\subsection{Decoding Nature of Architectural (Re)Program}

Insight into the applied types of the architectural program within conceptual models (Table 6-related to architectural programming types provided in Table 2)—conducted by identifying different relations in-between program elements, in-between program and form, as well as identifying functional performance-provides confirmation of the practiceoriented nature of the applied methodological framework. In addition, the possibility of the proposed methodological framework to develop different types of architectural programs according to the environmentally sensitive heritage framework is recognized. Considering the distribution of the applied types of the architectural program within different conceptual models, we can recognize specific clusters-cluster 1 (conceptual models 1, 7, 8, 9 and 12), cluster 2 (conceptual models 2 and 5) and cluster $3(3,10$ and 11). At the same time, conceptual models 4 and 6 have a specific distribution of the observed characteristics (index) concerning the applied types of the architectural program.

Table 6. Identification of applied types of an architectural program within conceptual models.

\begin{tabular}{|c|c|c|c|c|c|c|c|c|c|c|c|c|}
\hline \multirow{2}{*}{$\begin{array}{c}\text { Type of Architectural } \\
\text { Program }\end{array}$} & \multicolumn{12}{|c|}{ Conceptual Model } \\
\hline & 1 & 2 & 3 & 4 & 5 & 6 & 7 & 8 & 9 & 10 & 11 & 12 \\
\hline thematic & $\bullet$ & $\bullet$ & $\bullet$ & $\bullet$ & $\bullet$ & $\bullet$ & $\bullet$ & $\bullet$ & $\bullet$ & $\bullet$ & $\bullet$ & $\bullet$ \\
\hline disparate & & & $\bullet$ & $\bullet$ & & $\bullet$ & & & & $\bullet$ & $\bullet$ & \\
\hline reciprocity & & $\bullet$ & & & $\bullet$ & $\bullet$ & & & & & & \\
\hline indifference & $\bullet$ & & $\bullet$ & & & & $\bullet$ & $\bullet$ & $\bullet$ & $\bullet$ & $\bullet$ & $\bullet$ \\
\hline conflict & & & & $\bullet$ & & & & & & & & \\
\hline prescriptive & & & $\bullet$ & & & $\bullet$ & & & & $\bullet$ & • & \\
\hline spontaneous & $\bullet$ & $\bullet$ & $\bullet$ & $\bullet$ & $\bullet$ & $\bullet$ & $\bullet$ & $\bullet$ & $\bullet$ & $\bullet$ & $\bullet$ & $\bullet$ \\
\hline
\end{tabular}

The cross-examination of identified clusters in relation to multiscale and value-based track analysis indicates that the type of architectural program implemented within a particular conceptual model is related to programming values and the spatial levels of a particular concept generator.

The first cluster of conceptual models (1, 7, 8, 9 and 12) focuses on architectural intervention at the level of public spaces (community and block level) within the immediate environment of Genex Tower. It is based on a design strategy to fully preserve the building and affirm the thematic and spontaneous program, while the relationship between the form and program is indifference.

The second cluster of conceptual models ( 2 and 5 ) focuses on architectural intervention at the level of Genex Tower (building level). It is based on a design strategy to generate a new spatial configuration at the interior level and to affirm the thematic and spontaneous program, while the relationship of form and program is reciprocal.

The third cluster of conceptual models (3,10 and 11) focuses on architectural intervention at the level of a single spatial unit/room and activity setting. It is based on a design strategy to generate a new spatial configuration of residential units. The specificity of this cluster is reflected in the engagement of both the thematic and disparate programs in terms of hybridity and both the prescriptive and spontaneous programs in terms of the functional performance of space. The relationship of form and program is indifference, bearing in mind that the architectonics and spatial structure of Genex Tower are completely preserved.

Conceptual model 4 is primarily specific due to the conflict between form and program, while conceptual model 6 is specific due to the reciprocity of form and program. These two conceptual models have a focus on architectural intervention at the building. However, the design strategy is experimental in nature-it decomposes the form and more radically restructures the interior of the building resulting in a specific architectural program outcome. 
In a comprehensive understanding of the relationship between the types of architectural programs and conceptual models, it is recognized that all conceptual models have engaged thematic programs in terms of hybridity and spontaneous programs in terms of functional performance. On the other side, the disparate program is characteristic of conceptual models whose particular concept generator is a specific construct directed towards economic strengthening (such as circularity, tourism and the dichotomy of livingwork-leisure time). A prescriptive program in terms of functional performance occurs when the existing residential function of Genex Tower is retained, while the spontaneous program supplements additional variable activities.

\section{Conclusions}

By conducting all three levels of discussion (multiscale, value-based and architectural program types), the results indicate that the methodology of architectural programming is a complex process that can significantly improve the overall design process and its argumentative framework: (1) The value-based track has a significant role in identifying all determinants and contextual factors of architectural and urban heritage, (2) the multiscale track is an essential link between identified values and types of architectural program in the process of designing conceptual models, and (3) although types of the architectural program represent a general pattern of threefold relations (between program elements, between program and form and functional performance), they nevertheless provide insight into the initial strategy for creating conceptual models. Clustering the conceptual models according to the type of architectural program indicates a strong connection between spatial levels and the application of architectural programs. On the one hand, this clustering affirms the dependence between parts emphasizing the fragmentation of a form, while on the other side encourages functional performativity of physically porous spaces.

This research contributes to establishing initial scientific knowledge about the relationship between value-based programming approaches in architectural design and heritage construct. As previously introduced within the theoretical background, four programming approaches are equally important in architectural design practice-designbased, knowledge-based, agreement-based and value-based approaches. This research directly engaged a value-based approach as a methodological polygon, while a designbased approach was engaged within the conceptual models' development phase. These two approaches provide a strong foundation and a confirmation of the capacity of the architectural programming methodology to establish sustainable reconfigurations of modernist heritage. Concerning the relationship between architectural programming and the overall design process, it is recognized that the value-based approach has a dual role in this process: (1) before the design process as an analytical tool for identifying values and contextual factors and (2) after the design process as a framework for evaluation of design solution in line with recognized values. On the other hand, the design-based approach is engaged during the design process as an instrument for translating an idea into a design. Although the research engages certain participatory design methods in on-site research and interviews with Genex Tower residents in the first phase of conceptual model development, such a framework cannot be considered a sufficient basis for an integrated observation of all approaches. This fact can be recognized as a certain limitation of the study from the procedural aspect. The need for successful implementation of agreement-based and knowledge-based approaches generates suggestions and perspectives for further research. These two approaches could further encourage participatory programming and the active participation of users within the design process. In this context, it is essential to emphasize the value-participation knowledge bias. There is an evident need to explore the values and interests behind World Heritage Site management, balancing benefits and costs and the preservation and promotion interests [77].

The central characteristic of architectural programming in the procedural sense is reflected in the organizational aspect of the design process and the strengthening of architecture as a team discipline. During the design process, special attention should be paid to 
the distribution of roles of all participants in the process, including architects, future users and researchers from social sciences but also the clients/investors and authorities. The participatory dimension of programming is based on the belief that the participation of all actors in the design process should be carefully developed-through the development of new relationships between users and service providers, as well as the development of common tools and languages as catalysts for individual and community development. This kind of development becomes especially significant in the context of social wellbeing. According to Taçon and Baker, "heritage is something that is essential for contemporary and future well-being, and that if we do not better care for heritage then human health will be negatively impacted" [78]. However, the ability to enjoy and take part in culture must not be taken for granted, as numerous barriers need to be overcome: "financial barriers to overcome, and probably geographical, social, and cultural barriers" [79]. Thus, inclusive policies are needed to enable all local and foreign people to access heritage activities and, therefore, higher levels of subjective well-being [79].

Although wellbeing represents a fundamental dimension to express the nature of sustainability and can be recognized as the ultimate goal of sustainable development [41], in our view, recognizing its importance in the context of heritage protection, promotion and reuse is still lacking. The promotion of wellbeing in this context (both for tourists and residents) must go beyond the economic values and should ensure social wellbeing aspects.

In the context of modernist doctrine in architecture, the primary connections between environment-behavior relations were established with a focus on the human functional programming value. Today, an unsustainable present and an uncertain future require the obvious and unquestionable necessity of introducing a wide range of programming values in the process of heritage reprogramming.

The research points to a wide range of arguments for why environment-behavior relations, and specifically value-based methodological approach of architectural programming, are very promising in reprogramming modernist heritage but also heritage in general. Some of them are certainly as follows:

- The value-based programming approach enables a systematic overview of a large number of relationships between the environment and human behavior, as well as various aspects and characteristics of the environment in the broadest sense and their application in the design process. This approach involves much more than a functional and formal architectural analysis of heritage, including social, economic, systemic, environmental and temporal factors.

- The implications of this approach go beyond the physical appearance of heritage, highlighting a wide range of values and specific local context, which ultimately results in improved environmental quality and user satisfaction, i.e., improved aspects of wellbeing in the targeted area.

- Heritage aesthetics are also observed beyond the mere visual aspects in relation to user desires, the experience of space, tradition and, of course, user perception of the environment.

- In addition, numerous studies have shown that professional attitudes, preferences and values in relation to heritage are often very different from those of users and society. The value-based programming approach enables the identification of specific heritage values but also the needs of users, preferences and values in order to adequately use this information in the design process.

In this way, architectural practice becomes operational and performative in line with current needs and tendencies in heritage promotion, focusing on active environmental experience, as opposed to the concept of the disinterested contemplation of heritage as an exclusively material artefact.

This research contributes to the recognition of the potentials of value-based architectural programming approach as a systematic, operative and critical methodological framework in the design process of heritage promotion, protection and reuse. The results of this study encourage practitioners (planners, urban designers and architects) to consider the value- 
based programming approach and to find the correlation between (a) environment-behavior relations, (b) programming and heritage values and (c) social wellbeing.

Author Contributions: Conceptualization, J.R.T., A.M. and A.N.; methodology, J.R.T., A.M. and A.N.; conducting research with student group within Design Studio, A.N., J.R.T. and A.M.; writingoriginal draft preparation, J.R.T. and A.M.; writing—review and editing, A.N.; visualization, J.R.T. and A.M. All authors have read and agreed to the published version of the manuscript.

Funding: This research was funded by the Ministry of Education, Science and Technological Development of the Republic of Serbia, grant number 451-03-68/2020-14/200090.

Institutional Review Board Statement: Not applicable.

Informed Consent Statement: Not applicable.

Data Availability Statement: The datasets regarding 12 conceptual models are available on request from the corresponding author.

Acknowledgments: The research was realized within the Erasmus + Strategic Partnerships for Higher Education entitled Enhancing of Heritage Awareness and Sustainability of Built Environment in Architectural and Urban Design Higher Education (HERSUS). The authors would like to thank all the students who participated in the first phase of research within the design studio: Sofija Sinobad, Una Obradović, Danica Petrović, Dunja Dedić, Milica Mijajović, Nenad Pavlović, Andrej Jovanović, Katarina Spasojević, Jovana Prijović, Teodora Stevanović, Mihailo Milosavljević and Milica Knežević.

Conflicts of Interest: The authors declare no conflict of interest. The funders had no role in the design of the study; in the collection, analyses, or interpretation of data; in the writing of the manuscript, or in the decision to publish the results.

\section{References}

1. Architecture 2030. Existing Building Actions. Available online: https://Architecture2030.Org/Existing-Building-Actions/ (accessed on 1 August 2021).

2. Council of the European Union. Council Conclusions on the Work Plan for Culture 2019-2022. Off. J. Eur. Union 2018. Available online: https:/ / eur-lex.europa.eu/legal-content/EN/TXT/PDF/?uri=CELEX:52018XG1221(01)/ (accessed on 5 June 2021).

3. Council of the European Union. Council Resolution of 12 February 2001 on Architectural Quality in Urban and Rural Environments. Off. J. Eur. Union 2001. Available online: https://eur-lex.europa.eu/legal-content/EN/TXT/PDF/?uri=CELEX: 32001G0306(03) (accessed on 5 June 2021).

4. Swinburne, H. Change Is the Challenge. AIA J. 1967, 47, 83-90.

5. Architects' Council of Europe. Policy Position-Urban Regeneration: Renovating the Existing Building Stock 2016. Available online: https:/ / www.ace-cae.eu/fileadmin/New_Upload/7._Publications/Manifesto/EN/ACE_MANIFESTO_2_URBAN_20 16_EN_.pdf/ (accessed on 9 June 2021).

6. Architects' Council of Europe. Leeuwarden Declaration-Adaptive Re-Use of the Built Heritage: Preserving and Enhancing the Values of Our Built Heritage for Future Generations 2018. Available online: https://www.ace-cae.eu/uploads/tx_ jidocumentsview /LEEUWARDEN_STATEMENT_FINAL_EN-NEW.pdf/ (accessed on 9 June 2021).

7. International Union of Architects. Copenhagen Declaration-Sustainable by Design; UIA: Paris, France, 2009.

8. Özten, U. Why Architectural Program Today? In Proceedings of the SIGraDi 2009_Proceedings of the 13th Congress of the Iberoamerican Society of Digital Graphics, Sao Paulo, Brazil, 16 November 2009; pp. 343-345.

9. Roggema, R. Research by Design: Proposition for a Methodological Approach. Urban Sci. 2017, 1, 2. [CrossRef]

10. Cherry, E. Programming for Design—From Theory to Practice; John Willey \& Sons, Inc.: New York, NY, USA, 1999.

11. Stierli, M.; Kulić, V. Toward a Concrete Utopia: Architecture in Yugoslavia, 1948-1980; The Museum of Modern Art: New York, NY, USA, 2018.

12. Ristic Trajkovic, J. The Application of Environment-Behavior Theories in Architectural Design; University of Belgrade-Faculty of Architecture: Belgrade, Serbia, 2016.

13. Dayaratne, R. Environment- Behavior Research and the Practice of Architecture: Paradigms and Paradoxes. Built-Environ. Sri Lanka 2016, 3, 38-45. [CrossRef]

14. Gary, M. Environment, Behaviour and Society: A Brief Look at the Field and Some Current EBS Research at the University of Sydney. In Proceedings of the Spatial Environments Agreeable for Human Beings: Proceedings of the 6th International Symposium for Environment-Behavior Studies, Tianjin, China, 22-25 October 2004; Yuan, Y., Ed.; Baihua Literature and Art Publishing House: Tianjin, China, 2004; pp. 489-506.

15. Rapoport, A. Environment-Behavior Studies: Past, Present, and Future. J. Archit. Plan. Res. 2008, 25, $276-281$.

16. Akintunde, E.A. Theories and Concepts for Human Behavior in Environmental Preservation. J. Environ. Sci. Public Health 2017, 1, 120-133. [CrossRef] 
17. Broady, M. Planning for People: Essays on the Social Context of Planning; Bedford Square Press: London, UK, 1968.

18. Vujović, S. Gradsko stanovanje i privatnost u Srbiji tokom 20. veka. In Privatni Život kod Srba u Dvadesetom Veku; Ristanović, M., Ed.; Klio: Belgrade, Serbia, 2007.

19. Canter, D. Psychology for Architects; Elsevier Science Ltd.: London, UK, 1974.

20. Canter, D. Applying Psychology. Inaugural Lecture; University of Surrey: Guildford, UK, 1985.

21. Rapoport, A. Systems of Activities and Systems of Settings. In Domestic Architecture and the Use of Space; Kent, S., Ed.; Cambridge University Press: New York, NY, USA, 1990; pp. 9-20.

22. Altman, I. Privacy Regulation: Culturally Universal or Culturally Specific? J. Soc. Issues 1977, 33, 66-84. [CrossRef]

23. Moore, G. Environment-Behavior Studies. In Introduction to Architecture; Snyder, J., Catanese, A., Eds.; McGraw: New York, NY, USA, 1979; pp. 46-71.

24. Ghazali, E.M.; Nguyen, B.; Mutum, D.S.; Yap, S.-F. Pro-Environmental Behaviours and Value-Belief-Norm Theory: Assessing Unobserved Heterogeneity of Two Ethnic Groups. Sustainability 2019, 11, 3237. [CrossRef]

25. Stern, P.C. New Environmental Theories: Toward a Coherent Theory of Environmentally Significant Behavior. J. Soc. Issues 2000, 56, 407-424. [CrossRef]

26. Hungerford, H.R.; Volk, T.L. Changing Learner Behavior Through Environmental Education. J. Environ. Educ. 1990, $21,8-21$. [CrossRef]

27. Hines, J.M.; Hungerford, H.; Tomera, A.N. Analysis and Synthesis of Research on Responsible Environmental Behavior: A MetaAnalysis. J. Environ. Educ. 1987, 18, 1-8. [CrossRef]

28. Ajzen, I. Perceived Behavioral Control, Self-Efficacy, Locus of Control, and the Theory of Planned Behavior. J. Appl. Soc. Psychol. 2002, 32, 665-683. [CrossRef]

29. Ajzen, I. The Theory of Planned Behavior. Theor. Cogn. Self-Regul. 1991, 50, 179-211. [CrossRef]

30. Heimlich, J.E.; Ardoin, N.M. Understanding Behavior to Understand Behavior Change: A Literature Review. Environ. Educ. Res. 2008, 14, 215-237. [CrossRef]

31. Heimlich, J.E.; Hammond, A.; Adriaanse, A.; Rodenburg, E.; Bryant, D.; Woodward, R. Environmental Indicators: A Systematic Approach to Measuring and Reporting on Environmental Policy Performance in the Context of Sustainable Development; World Resources Institute: Washington, DC, USA, 1995.

32. Janz, N.K.; Becker, M.H. The Health Belief Model: A Decade Later. Health Educ. Q. 1984, 11, 1-47. [CrossRef]

33. Stern, P.C.; Dietz, T.M.; Abel, T.; Guagnano, G.A.; Kalof, L. A Value-Belief-Norm Theory of Support for Social Movements: The Case of Environmental Concern. Hum. Ecol. Rev. 1999, 6, 81-97.

34. Schwartz, S.H. Universals in the Content and Structure of Values: Theoretical Advances and Empirical Tests in 20 Countries. In Advances in Experimental Social Psychology; Zanna, M.P., Ed.; Academic Press: Cambridge, MA, USA, 1992; Volume 25, pp. 1-65, ISBN 0065-2601.

35. Schwartz, S.H. Are There Universal Aspects in the Structure and Contents of Human Values? J. Soc. Issues 1994, 50, 19-45. [CrossRef]

36. Van der Werff, E.; Steg, L. The Psychology of Participation and Interest in Smart Energy Systems: Comparing the Value-BeliefNorm Theory and the Value-Identity-Personal Norm Model. Energy Res. Soc. Sci. 2016, 22, 107-114. [CrossRef]

37. Choi, H.; Jang, J.; Kandampully, J. Application of the Extended VBN Theory to Understand Consumers' Decisions about Green Hotels. Int. J. Hosp. Manag. 2015, 51, 87-95. [CrossRef]

38. Corey Lee, M. Keyes Social Well-Being. Soc. Psychol. Q. 1998, 61, 121-140. [CrossRef]

39. Teghe, D.; Rendell, K. Social Wellbeing: A Literature Review; School of Social Work \& Welfare Studies, CQU: Rockhampton, Australia, 2005. [CrossRef]

40. Nocca, F. The Role of Cultural Heritage in Sustainable Development: Multidimensional Indicators as Decision-Making Tool. Sustainability 2017, 9, 1882. [CrossRef]

41. United Nations. The Future We Want: Final Document of the Rio +20 Conference. In Proceedings of the Rio20 United Nations Conference Sustainable Development, Rio de Janeiro, Brazil, 20-22 June 2012.

42. Nocca, F.; Girard, L.F. Towards an Integrated Evaluation Approach for Cultural Urban Landscape Conservation/Regeneration. Region 2018, 5, 33-51. [CrossRef]

43. Pena, W.M.; Fock, J.W. Problem Seeking: New Directions in Architectural Programming; Caudill Rowlett Scott Houston: Houston, TX, USA, 1969.

44. Lawrence, A.R.; Schafer, A. Re: Programming_Journal of Writing + Building; Praxis: Columbus, OH, USA, 2006 ; pp. 4-5.

45. Pyburn, J. Architectural Programming and the Adaptation of Historic Modern Era Buildings for New Uses. J. Archit. Conserv. 2017, 23, 12-26. [CrossRef]

46. Pena, W.; Caudill, W. Architectural Analysis-Prelude to Good Design. Archit. Rec. 1959, 125, $178-182$.

47. Anderson, L.B. The Environmental Design Umbrella. J. Archit. Educ. 1967, 21, 4-6. [CrossRef]

48. Milne, G. A Comparison of Paradigms in Research, Design and Education. J. Archit. Educ. 1971, 26, 8-15. [CrossRef]

49. Zeisel, J. Sociology and Architectural Design; Russell Sage Foundation: New York, NY, USA, 1975.

50. Horowitz, H. The Architect's Programme and the Behavioural Sciences. Archit. Sci. Rev. 1966, 9, 71-79. [CrossRef]

51. Studer, R.G.; Stea, D. Architectural Programming, Environmental Design, and Human Behavior. J. Soc. Issues 1966, 22, 127-136. [CrossRef] 
52. Summerson, J. The Case for a Theory of Modern Architecture. R. Inst. Br. Archit. J. 1957, 307-310.

53. Hoppenfeld, M. Towards a Consensus of Approach to Urban Design. AIA J. 1962, 38, 37-42.

54. Peña, W.; Parshall, S. Problem Seeking: An Architectural Primer, 5th ed.; John Wiley \& Sons: Hoboken, NJ, USA, 2012.

55. Hershberger, R. Architectural Programming and Predesign Manager; The McGraw-Hill Companies, Inc.: New York, NY, USA, 1999.

56. Values in Heritage Management: Emerging Approaches and Research Directions; Avrami, E.; McDonald, S.; Mason, R.; Myers, D. (Eds.) Getty Conservation Institute: Los Angeles, CA, USA, 2020.

57. Fredheim, L.H.; Khalaf, M. The Significance of Values: Heritage Value Typologies Re-Examined. Int. J. Herit. Stud. 2016, 22, 466-481. [CrossRef]

58. Herschberger, R.G. Values: A theoretical framework for architectural programming. In Programming the Built Environment; Preiser, W.F.E., Ed.; Van Nostrand Reinhold: New York, NY, USA, 1985; pp. 7-12.

59. Fenton, J. Pamphlet Architecture 11: Hybrid Buildings; Princeton Architectural Press: New York, NY, USA, 1985.

60. Tschumi, B. Architecture and Disjunction; MIT Press: Cambridge, MA, USA, 1996.

61. James, V.; Yoos, J. Tempering Program_Journal of Writing + Building; Praxis: Columbus, OH, USA, 2006; pp. 30-35.

62. Danuta Niezabitowska, E. Research Methods and Techniques in Architecture; Routledge: New York, NY, USA, 2018.

63. Salama, A. Teaching Architectural Programming: Cultivating a Culture of an Inquiry-Based and a Process-Centred Design Pedagogy. Archit. Constr. Russ. 2017, 2, 30-45.

64. Mugerauer, R. Interpreting Environments: Tradition, Deconstruction, Hermeneutics; University of Texas Press: Austin, TX, USA, 1995.

65. Miles, M.B.; Huberman, M. Qualitative Data Analysis: An Expanded Sourcebook, 2nd ed.; Sage Publications: Thousand Oaks, CA, USA, 1994.

66. Trajković Ristić, J.; Stojiljković, D.; Ćirić, D. Transformation of Modern Urban Space of New Belgrade in the Conditions of the Post-Socialist Transition and Sustainable Development. In Proceedings of the 12th Internacional Docomomo Conference: The Survival of Modern from Coffee Cup to Plan, Docomomo, Finland, 7-10 August 2013; pp. 381-388.

67. Djokić, V.; Ristić Trajković, J.; Krstić, V. An Environmental Critique: Impact of Socialist Ideology on the Ecological and Cultural Sensitivity of Belgrade's Large-Scale Residential Settlements. Sustainability 2016, 8, 914. [CrossRef]

68. Jovanović-Nenadović, L. Koncepcija Projektovanja Stambenih Jedinica u Novom Beogradu—Analiza Konkursnih Rešenja u Periodu 1966-1975. Godine; University of Belgrade-Faculty of Architecture: Belgrade, Serbia, 2011.

69. Ristić Trajković, J.; Stojiljković, D. Sustainability and Socialism: Socio-Ecological Ideas in the Urbanization of New Belgrade. Facta Univ. Ser. Archit. Civ. Eng. 2016, 14, 343-353. [CrossRef]

70. De Certeau, M. The Practice of Everyday Life; University of California Press: Berkeley, CA, USA, 1984.

71. Trajković, J.; Stojiljković, D.; Međo, V. Influence of the Socialist Ideology on the Conception of Multi-Family Housing: New Urban Landscape and the Typological Models of Housing Units. Facta Univ. Ser. Archit. Civ. Eng. 2015, 13, 167-179. [CrossRef]

72. Browning, W.D.; Ryan, C.O.; Clancy, J.O. 14 Patterns of Biophilic Design; Terrapin Bright Green, LLC.: New York, NY, USA, 2014.

73. Corbusier, L. Toward an Architecture; Getty Research Institute: Los Angeles, CA, USA, 2007.

74. Nicic, M.; Iguman, S. Post-Socialism and “Ordinary” Tourism: New Belgrade. Int. J. Tour. Cities 2019, 5, 307-325. [CrossRef]

75. Ribnikar, V. Problem Stambenih Zgrada. Arhit. Zagreb 1950, 11-12, 19.

76. Radna Grupa D. Kako Početi Život u Novom Naselju—Problemi Identifikacije i Socijalne Segregacije. In Budućnost Stambenih Naselja Plan. Programiranje Urban. Proj. Realiz. Korišćenje Komun; Knjiga 5-Završni Izveštaji i Rezimei; 77; CEP: Beograd, Yugoslavia, 1977.

77. Parga-Dans, E.; Alonso-González, P.; Otero Enríquez, R. The Social Value of Heritage: Balancing the Promotion-Preservation Relationship in the Altamira World Heritage Site, Spain. J. Destin. Mark. Manag. 2020, 18, 100499. [CrossRef]

78. Taçon, P.S.C.; Baker, S. New and Emerging Challenges to Heritage and Well-Being: A Critical Review. Heritage 2019, $2,84$. [CrossRef]

79. Ateca-Amestoy, V.; Villarroya, A.; Wiesand, A.J. Heritage Engagement and Subjective Well-Being in the European Union. Sustainability 2021, 13, 9623. [CrossRef] 